\title{
Broken Agreement
}

\author{
Kathryn Bock and Carol A. Miller
}

\begin{abstract}
Michigan State University
The subjects and verbs of English sentences agree in number. This superficially simple syntactic operation is regularly implemented by speakers, but occasionally derails in sentences such as The cost of the improvements have not yet been estimated. We examined whether the incidence of such errors was related to the presence of subject-like semantic features in the immediate preverbal nouns, in light of current questions about the semantic versus syntactic nature of sentence subjects and the interactivity of language processing. In three experiments, speakers completed sentence fragments designed to elicit erroneous agreement. We varied the number and animacy of the head noun and the immediate preverbal (local) noun, as well as the amount of material separating the head noun from the verb. The plurality of the local noun phrase had a large and reliable effect on the incidence of agreement errors, but neither its animacy nor its length affected their occurrence. The latter findings suggest, respectively, that the semantic features of sentence subjects are of minimal relevance to the syntactic and morphological processes that implement agrecment, and that agreement features are specified at a point in processing where the eventual length of sentential constituents has little effect on syntactic planning. Both results follow naturally from explanations of language production that emphasize the segregation of sentence formulation processes into relatively autonomous components. O 1991 Academic Press, Inc.
\end{abstract}

From time to time, The New Yorker reprints lapses in grammar from the nation's press. One that appeared recently was an excerpt from the report of a survey conducted by a New York City newspaper. Those who were surveyed responded to the question "Efforts to make English the official language is gaining strength throughout the U.S. What is your reaction?" The New Yorker's was brief: "It's hopeless" (November 17, 1986, p. 94).

This research was supported by National Institutes of Health Grant R01 HD21011. The participation of the second author was partially supported by a Research Experience for Undergraduates supplement from the National Science Foundation to Grant BNS 86-17659. We thank Jill Beckman, Karen Chapman, Kathleen Eberhard, David Irwin, Helga Loebell, Randal Morey, Brad Rakerd, and James Zacks for their assistance, Joseph Danks and Jane Oakhill for directing us to the book by Mann (1982b), and Robert Beard, Gary Dell, Gerard Kempen. David Meyer, Elissa Newport, Joseph Stemberger, and Rose Zacks for good questions and advice. Special thanks to Anne Cutler for providing her corpus of agreement errors along with her editorial counsel, and to the Brians Butterworth and MacWhinney for bracing reviews. A preliminary report of this work was presented at the meeting of the Psychonomic Society in November, 1988. Send requests for reprints and other correspondence to Kathryn Bock, Department of Psychology, Psychology Research Building, Michigan State University, East Lansing, MI 48824-1117. 
This ironic judgment was prompted by the failure of the verb in the question to agree in number with the head of the subject noun phrase: Efforts is plural, and requires not the singular auxiliary is, but the thirdperson plural are. As syntactic errors go, such agreement failures are rather frequent. Some additional examples, all drawn from spoken English, are shown in (1) through (4):

(1) The time for fun and games are over.

(2) The readiness of our conventional forces are at an all-time low.

(3) I don't think it much matters where the final reinterment of these men are.

(4) The learning skills people have entering college is less than it should be.

All of these errors have the same feature: The head noun and the verb are separated by another noun phrase that disagrees with the subject in number. The result is a phenomenon that has been called proximity concord (Quirk, Greenbaum, Leech, \& Svartvik, 1972), since the verb agrees in number with the proximal or local noun phrase rather than the more distant head noun.

Like other speech errors, aberrations of verb agreement may reveal something about the normal components of language production (Dell, 1986; Fromkin, 1971; Garrett, 1975; Stemberger, 1985). They especially promise an interesting glimpse into syntactic mechanisms, for two reasons. First, agreement represents a classic case of syntactic dependency (Lyons, 1969), where information that controls the form of one element of a sentence may be separated from it, and so must be retrieved later or maintained in the meantime. Thus, although the subject and verb are often contiguous, it is not uncommon for them to be interrupted by a phrase or clause or more. This commonly occurs with nominal postmodifiers such as relative clauses (The report that the former president read was short), appositive or noun-phrase complement clauses (The report that the former president could read was unverifiable), and prepositional phrases (The report of the former president was rejected). ${ }^{1}$ Second, subject-verb number agreement is perhaps the most straightforward and clearly syntactic of all syntactic operations. It is straightforward because it has relatively few exceptions: Almost all head subject nouns that are grammatically plural require the plural forms of those verbs that are marked for number. And it appears to be clearly syntactic because the noun phrase that the verb agrees with is almost always the highest noun phrase in the clause, in a purely configurational sense.

\footnotetext{
${ }^{1}$ Of these, prepositional-phrase postmodifiers are most common; according to Quirk et al. (1972), they are three to four times more frequent than clausal postmodifiers.
} 
In this paper we will be concerned primarily with what agreement errors might reveal about the nature of sentential subjects, specifically the features of the subject that are accessible to the agreement operation. Our concerns touch on a central point of contrast between different perspectives on language production, one involving the question of the interactivity or isolability of processing (see Butterworth, 1980 for an analysis of these notions in terms of production models). This contrast has surfaced in the study of various kinds of lexical errors (compare Baars, Motley, \& MacKay, 1975; Dell \& Reich, 1981; Harley, 1984; Martin, Weisberg, \& Saffran, 1989; and Stemberger, 1985 with Fay \& Cutler, 1977; Garrett, 1975, 1980; and Levelt, 1983), phonological errors (compare Dell, 1986 with Shattuck-Hufnagel, 1979), and variations of word ordering (compare Bock, 1987a with Levelt \& Maassen, 1981).

The importance of this issue for explanations of language production and language performance in general lies in its relevance to the characterization of processing domains and processing vocabularies. The representations and mechanisms that have been emphasized in cognitive theory are, properly, those that serve in the interpretation of experience and the direction of goal-oriented action. To the extent that language performance is of a piece with general processes of cognition (Anderson, 1983), appropriate theoretical constructs may be drawn from or reduced to the representations and mechanisms of human thought, broadly defined, so that the interpretative and directive functions of the mind may emerge from ongoing interactions among similarly constituted components and processes, any or all of which may contribute to the interpretation and creation of utterances. Alternatively, language performance may represent just one of several highly differentiated components or modules of cognition (Fodor, 1983), each of which is constituted of unique representations or mechanisms that have little in common, and in consequence have limited lines of communication with one another. On such a view, the contributions from components of general cognition or central processing to utterance interpretation and creation will be heavily restricted.

These different perspectives on the nature of cognition have different implications for explanations of language production (Bock \& Kroch, 1989; Bock \& Loebell, 1990), as well as language learning and understanding. The general question in production is how a speaker casts a to-be-communicated nonverbal thought or message into a lexically and syntactically elaborated utterance. The message is full of meaning; the utterance is full of sound. In the transition from one to the other, the ability of the features of the message to exert fine control over the features of the utterance represents one test of the extent to which there are 
open versus highly restricted interactions among the kinds of information involved in language processing.

Errors of number agreement tie into this question in a surprisingly direct way. In the history of languages, agreement markers are closely related to pronominal elements, evolving as reduced forms of those elements (Givón, 1976). Since pronouns are customarily used only when their referents are recoverable from the discourse context, that is, when their referents are topics of the discourse, Givon hypothesizes that agreement marking may be similarly linked to topicalization. Accordingly, he suggests that the phenomena that are identified with subject-verb agreement may in fact reflect topic-verb agreement. The implication is that those things that are most likely to be topics (e.g., humans, nonhuman animates, definites) are also most likely to control grammatical agreement. A similar notional hierarchy governs agreement resolution principles, which determine which of several conjoined nouns controls agreement when the nouns conflict on some attribute involved in the agreement system of a language (Corbett, 1988; Klaiman, 1988).

The notional correlates of topicality appear to play a minimal role in the English agreement system, since agreement seems to be structurally rather than semantically controlled. However, to the extent that language processing is open to all of the features of messages, and those features are capable of influencing the details of utterance formation, we might expect to see them at work at the edges of the agreement system, particularly where violations of the accepted canons of grammaticality are common. Because animacy and definiteness are highly correlated with subjecthood in English (Clark \& Begun, 1971; Corrigan, 1986; Dewart, 1979; Ransom, 1977), and because English speakers are biased to treat preverbal nouns as sentence subjects (Bates, McNew, MacWhinney, Devescovi, \& Smith, 1982; MacWhinney, Bates, \& Kliegl, 1984), it is easy to imagine that subject-verb agreement would derail most often when the head subject noun has few of the prototypical features of subjects, and a preverbal noun has many of them. An error of agreement such as The blanket on the babies were small might therefore be more probable than one such as The baby on the blankets were small. Since the error manifestly consists of agreement between the verb and the wrong noun, it is natural to look to the semantic characteristics of that noun for an explanation of the problem, particularly from the perspective of claims about continuous interactivity between the features of messages and the mechanisms that form sentences. ${ }^{2}$

${ }^{2}$ It is important to recognize the dangers of extrapolating from comprehension to production (Clark \& Malt, 1984). However, the strongest hypotheses about language performance are those that presume symmetrical uses of language knowledge across performance 
A different prediction emerges from views of production that emphasize restrictions on the role of semantic factors in syntactic formulation (Garrett, 1976; Levelt, 1989), and, more specifically, from an approach that regards syntactic relations such as subject as primitives of one level of the adult language production system (Bock, 1987b; Bock \& Warren, 1985; Kempen \& Hoenkamp, 1987; Levelt, 1989). On this view, the notional features of the elements of a nonlinguistic message may differentiate their chances of being assigned to the subject relation, but are unlikely to influence their status with respect to the syntactic mechanisms of the production system. Thus, although animate message elements should indeed be more likely than inanimate ones to be granted subjecthood, once they are assigned, their-privileges with respect to the syntactic processing system may be identical. As a result, variations in the distribution of agreement errors may be relatively unaffected by the semantic features of any elements assigned to the subject relation.

This was the central issue that our research was designed to address. To help set the stage for the experiments, the next section briefly reviews the traditional linguistic facts of number agreement in English (mostly following Quirk et al., 1972), setting aside some of the complexities that are not immediately relevant to the present work. We then survey additional linguistic perspectives on the possible role of semantic factors in English verb agreement, and summarize various claims and findings about verb-agreement errors from the sparse literature that deals with them. Along the way, we lay out some of the subsidiary questions addressed in the experiments we will report.

\section{SUBJECT-VERB AGREEMENT IN ENGLISH}

The traditional description. The simple rule of subject-verb agreement (or concord) is that a singular subject takes a singular verb and a plural subject takes a plural verb. Implementing the rule requires knowing, among other things, (1) how to mark number on verbs and nouns, (2) how to identify the number of a subject, and (3) how to identify the subject of a verb.

With respect to marking number, the system for English verbs is a minimalist one: Except for $b e$, verbs mark the singular differently from the plural only in the third person present (The boy runs versus The boys run). Be marks number in both the present and past tenses, for first and

systems (e.g., Bresnan \& Kaplan, 1984), and from this standpoint it is important to evaluate whether the forces evident in language comprehension operate with similar effects in language production. Of course, a failure to find such symmetry may not damage those theories of comprehension that emphasize the interactivity of language processing so much as the presumption of symmetry itself. 
third persons. Nouns, in contrast, nearly always mark number if they are in the class of count rather than mass nouns. The vast majority take the regular plural inflection $(/ \mathrm{s} /, / \mathrm{z} /$, or $/ \mathrm{az} /)$. Those that form the plural irregularly nonetheless mark the singular and plural differently, except for a small number that have invariant singular and plural forms (zero plurals such as salmon in This salmon is huge versus These salmon are huge).

The presence of a grammatical marker for plurality is very closely linked to the idea of plurality, or notional plurality. However, notional plurality is sometimes unclear, and even when it is clear, it is not a completely reliable guide to grammatical plurality or number agreement: There are some categories of nouns for which notional and grammatical plurality diverge. One category is composed of the pluralia tantum nouns, nouns that are notionally singular but grammatically plural and take plural marking on the verb (trousers, binoculars). Some nouns are notionally plural and take plural marking on the verb, though the nouns themselves are uninflected for plurality (people, cattle, police); others are notionally plural and take singular marking on the verb, though they are likewise uninflected (team, committee). The occasional arbitrariness of linguistic number is evident in the difference between American and British English in the treatment of nouns of the latter sort (which also include public, audience, and government, among others): In British English, such nouns may take plural-agreeing verbs. Collective nouns may sometimes take either a singular or plural verb depending on whether the collective is viewed as a unit or as multiple individuals (The United Nations is/are headquartered in New York City). Agreement with indefinite expressions of amount (a number of cats; a lot of the boys) sometimes varies along similar dimensions, but in colloquial American English such expressions are more often treated as plurals with respect to verb agreement.

The identification of a verb's syntactic subject is generally straightforward, but becomes somewhat more complicated in the kinds of constructions we will be examining. Quirk et al. (1972) characterize the subject of a declarative sentence as the noun phrase that occurs before the verb phrase in a declarative clause. Though accurate, the characterization may be sharpened to make explicit the hierarchical structure that underlies standard agreement practices in English. The requisite clarification is that the verb agrees not with the number of the local noun phrase that immediately precedes it (excluding indefinite expressions of amount) but with the number of the highest noun phrase that immediately precedes it in the same clause (compare The bridges to the island were damaged by the hurricane with the generally unacceptable The bridges to the island was damaged by the hurricane). In terms of phrase structure, the subject is the noun phrase dominated by the sentence symbol (Bach, 1974). 
The semantics of subject-verb agreement. Because the English agreement system is relatively impoverished in comparison to the systems of other languages (where we find such extremes as the Bantu languages, which have upwards of 13 noun categories that require agreement not only between subject and verb but between verb and object; Demuth, 1988), it appears to pose few linguistic challenges (but see Morgan, 1972) and has received comparatively little linguistic attention. However, recent interest has been sparked by certain claims of generalized phrasestructure grammar (Gazdar, Klein, Pullum, \& Sag, 1985). An important feature of this approach is the effort to link structural distinctions directly to semantic interpretations, and agreement has been treated from this standpoint. One fact to be explained is that English verbs agree with noun phrases on such nominal features as number, gender, and person; nouns do not agree with verbs on such verbal features as tense and aspect (Sells, 1985). To capture this formally, the number, gender, and person features on the verb are controlled by the corresponding features of the subject noun phrase.

The features on the noun phrase, in turn, may be determined by the nature of the entities to which the noun phrase refers. As a result, the accuracy of a particular predicate with respect to its subject will be controlled by the nature of the subject's referent (Keenan, 1974), and what establishes the referent may vary from one construction to another. Keenan observed that in restrictive relative clauses, such as the woman who Richard likes, fixing the reference involves mentally restricting the set of all women to just the one of whom it is true that she is liked by Richard. For example, felicitous use of such an expression would occur in a context where the intended referent must be set apart from other women, not from other things that Richard likes. Conversely, in inalienable possessive constructions such as the interior of the car, the "possessor" (the car) must be identified, and then its interior, rather than the other way around. Here, then, one is unlikely to conceive of the set of all interiors and pick from them the one that the car happens to have.

Extrapolated to number agreement (as in Pollard \& Sag, 1988), this argument predicts that the number that appears on the verb may tend to agree with the number of the mentally identified referent of the subject. For a subject noun phrase such as the bridge to the islands, the specified referent is the single bridge that serves as the gateway to several islands, rather than the islands themselves. Conversely, for a subject noun phrase such as the picture on the postcards, the picture is part of ("possessed by") each of several postcards. Here, then, the referent is only abstractly singular; concretely, it encompasses the identical pictures of multiple postcards. If agreement tends to reflect the judged numerosity of the 
referent of the subject noun phrase, we might expect more "errors" to accompany a subject noun phrase such as The picture on the postcards than one such as The bridge to the islands (see Danks, 1984, for a similar prediction). The design of the materials for the first experiment allowed a preliminary evaluation of this possibility.

Errors of subject-verb agreement: Linguistic descriptions. Errors in syntax lie far outside the mainstream of the concerns of modern linguistics, and errors of subject-verb agreement are no exception. Errors of all sorts, to the extent that they are recognizable as errors by those who produce them, represent deviations from the grammar known by the speaker, and are absent from the agenda of generative grammarians. Instead, they fall into the class of "such grammatically irrelevant conditions as memory limitations, distractions, shifts of attention and interest, and errors (random or characteristic) in applying [onc's] knowledge of the language in actual performance" (Chomsky, 1965, p. 3).

Traditional and prescriptive grammarians have shown somewhat more interest in the error class represented in The time for fun and games are over, dubbing the phenomenon attraction, and offering (respectively) descriptions and excoriations of it. The descriptions emphasize the feature noted earlier, that there is a tendency for the verb to erroneously agree with other noun phrases that precede it more immediately than the head noun (e.g., Zandvoort, 1961), and the prescriptions against it follow directly: Writer and speakers are warned against the lapses of vigilance that allow such errors to appear. Fowler $(1937$, p. 389) wrote that

Some writers are as easily drawn off the scent as young hounds. They start with a
singular subject; before they reach the verb, a plural noun attached to an of or the
like happens to cross, \& off they go in the plural; or vice versa. This is a matter of
carelessness or inexperience only ...

and school grammars responded by drilling students on the offending constructions (e.g., Warriner, Renison, \& Griffith, 1965, Chap. 6).

An alternative approach to attraction, one that assimilates it to the antiprescriptivist concerns of contemporary linguistics, is to regard it not as an error but as a principled or rule-governed deviation from the more common agreement pattern (an idea consonant with the reference-based hypothesis formulated above) or as a dialectal variant of or ongoing change in the standard agreement rule (Francis, 1986). To the extent that speakers actually follow a rule that specifies agreement between local nouns and verbs, either as a dialectal option or a semantically driven principle, variations in agreement may be of somewhat more linguistic consequence. It is this sort of possibility that justifies regarding attraction as a type of proximity concord (Quirk et al., 1972). 
However, an implicit challenge to these explanations may be found in some of the traditional descriptions of attraction. Strang (1966) observed in a sample of written, educated British English (final examination papers of honors English students, all native English speakers) that attraction occurred primarily between plural local nouns and the subsequent verb, with 38 of 46 errors (83\%) displaying this pattern; Follett (1966) and Zandvoort (1961) alluded to a similar distribution. Our classifications of errors in published (Francis, 1986) and unpublished agreement error corpora ${ }^{3}$ strongly support Strang's suggestion: Across all of the corpora available to us, plurals accounted for $82 \%$ of the 83 recorded cases of attraction. ${ }^{4}$ Since the dialectal and reference-based accounts make no a priori distinction between plural and singular local nouns in licensing verb agreement, their credibility would be weakened by experimental confirmation of the asymmetry between singular and plural local nouns. The design of our experiments also permits this test.

Errors of subject-verb agreement: Psychological treatments. Most of the recent psycholinguistic literature that touches on subject-verb agreement has emphasized the notable indifference that English readers and listeners display to agreement violations (Kilborn, 1988; Kutas \& Hillyard, 1983; MacWhinney et al., 1984), relative to their sensitivity to semantic violations or incongruities. This stands in conflict with the general observance of appropriate agreement that obtains in speech, a conflict that is salient in some observations of four year olds reported by Keeney and Wolfe (1972). In their speech, the children correctly marked agreement on $94 \%$ of the verbs they produced, yet they responded at chance on a test in which they were asked to indicate which of two pictures (e.g., pictures of one versus two singing birds) went with descriptions such as is singing or are singing. In two other forced-choice comprehension tests, the proportions of correct responses significantly exceeded chance, but barely: The proportion of correct responses averaged .58. This evident

\footnotetext{
${ }^{3}$ In addition to our own small sample of errors, these included more extensive collections that were very generously donated by Anne Cutler and Jane Oakhill.

${ }^{4}$ The remarkable convergence between the results for these corpora and Strang's obscures potential differences whose importance remains to be assessed. Among these is the difference between errors in speech and in writing. All of Strang's errors occurred in writing; those in the combined corpora are of mixed origins. In the combined corpora, the plural proportions for errors recorded from spoken and written sources were .91 and .66 , respectively, for the 54 and 29 errors of each type. For many of these cases, however, the medium in which the error originated is indeterminate, especially errors that appeared in quotations of speech printed in newspapers and magazines (which were classified as written errors), or errors that occurred in speeches given from written texts (which were classified as spoken errors). Such problems aside, the observational record points consistently toward a plural bias among the errors.
} 
disparity between the apprehension of the conceptual correlates of agreement and the implementation of agreement in speech helps to confirm the tenuous link between meaning and form in the English agreement system.

With regard to the actual production of agreement errors, Woodworth (1938, p. 817) characterized the phenomenon of attraction in terms of the atmosphere effect that plagues syllogistic reasoning, suggesting that the verb agrees with the singular or plural "atmosphere" of the subject phrase, rather than the number of the head noun itself. In the same vein, Mann (1982a,b) pursued a prodigious and pioneering program of research on verb agreement. Mann asked students to provide verbs for sentences such as The sheep tested by the scientist on Saturday . . . very ill and The sheep tested by the scientists on Saturdays . . very ill. Generally, Mann's results conform to the suggestion that the greater the number of plurals preceding the verb the more likely it is that a plural verb form will be used.

Because the head nouns in most of the sentences employed by Mann were ambiguous in number, the number of the verb never created an outright error. However, some of Mann's experiments included sentences that could have elicited errors, and sometimes did, though at very low and generally nonsignificant rates. These results are difficult to interpret because, as Danks (1984) noted in his review of the work, essential control conditions were missing, including cases in which the intervening nouns were singular rather than plural. Furthermore, the nature of the presentation (the sentences were printed, with a blank where the verb belonged) allowed metalinguistic problem solving to overlay the processes of normal production. The conclusions (especially those of Mann, 1982b) emphasized the role of a general plural atmosphere in the induction of plural agreement, leaving open all questions about which plural or singular nouns might attract agreement, especially spurious agreement.

Mann's experiments (1982a) also briefly addressed a classic notion about the cause of agreement errors, formulated by Jespersen as follows: "It may be that if the verb comes long after its subject, there is no more mental energy left to remember what was the number of the subject" (1924, p. 345). If true, agreement errors may present the premier example of a performance-based error in the application of grammatical knowledge, of the sort that Chomsky (1965) seems to have had in mind. Mann found no consistent effects of this variable, but this may have been because the printed presentation made the head noun continuously accessible, minimizing demands on memory. To provide a fairer assessment, our first experiment included a manipulation of the length of the interruption between the head noun and the verb, under conditions that more closely approximated the conditions of ordinary speech. 


\section{EXPERIMENT 1}

In our initial study, we set out to see if we could induce agreement errors in the laboratory, and determine some of the boundary conditions on their occurrence. The participants received a variety of sentence preambles like those shown in Table 1. These duplicated the features that have been implicated in spontaneous agreement errors, having a head noun phrase that was followed by another noun phrase, the local noun, that mismatched the subject in number. So, if the head noun was singular the local noun was plural, and vice versa. The control preambles were identical except that the head and local nouns matched in number.

The participants listened to the preambles and repeated them back along with conclusions that turned them into complete sentences. Our examination focused on the verbs produced in the conclusions, whether they were marked for number, and whether this marking was incorrect with respect to the number of the subject as configurationally defined. If the sentence completion task successfully elicited agreement errors, we expected to find substantially more mistakes in the experimental (number mismatch) than in the control (number match) conditions. In the control conditions, the only factors that ought to produce errors are dialectal variations in number agreement (some dialects of English do not mark it), fluctuations in memory and attention, and failures of perception on the part of the speakers or the experimenters.

As Table 1 reflects, we also systematically varied the amount of material separating the head and local noun, so there was a short-postmodifier version of each preamble, as well as a long-postmodifier version. This length manipulation addressed the role of systematic memory problems in agreement, examining whether agreement errors tend to occur when speakers lose track of the head noun or its number, and fall back on the features of the local noun. If so, there should be more errors with long than with short postmodifiers.

To begin to evaluate the contributions of other factors to the occurrence of errors, the preambles in each condition differed on two other dimensions. First, as another check on the role of memory in implementing agreement, half of the preambles included prepositional phrase postmodifiers, and half included clausal (both subject- and object-relative) postmodifiers. Second, to examine effects of referential variations on the occurrence of errors, we included two types of prepositional phrase preambles. We will call these single-token and multiple-token preambles, for the reasons described earlier. Single-token items are exemplified by the preambles the bridge to the islands and the key to the cabinets. In these, the head was an individual token of a conceptual type that was unlikely to 
TABLE 1

Examples of Sentence Preambles from Experiment 1

\begin{tabular}{|c|c|c|}
\hline \multirow[b]{2}{*}{ Number condition } & \multicolumn{2}{|c|}{ Length condition } \\
\hline & Short preambles & Long preambles \\
\hline & \multicolumn{2}{|c|}{ Mismatch conditions } \\
\hline \multirow[t]{4}{*}{$\begin{array}{l}\text { Singular subject, } \\
\text { plural local noun }\end{array}$} & The key to the cabinets & $\begin{array}{l}\text { The key to the ornate } \\
\text { Victorian cabinets }\end{array}$ \\
\hline & The label on the bottles & $\begin{array}{l}\text { The label on the tamper- } \\
\text { proof medicine bottles }\end{array}$ \\
\hline & $\begin{array}{l}\text { The boy that liked the } \\
\text { snakes }\end{array}$ & $\begin{array}{l}\text { The boy that liked the } \\
\text { colorful garter snakes }\end{array}$ \\
\hline & $\begin{array}{l}\text { The soldier that the } \\
\text { officers accused }\end{array}$ & $\begin{array}{l}\text { The soldier that the } \\
\text { battalion's senior } \\
\text { officers accused }\end{array}$ \\
\hline \multirow{5}{*}{$\begin{array}{l}\text { Plural subject, } \\
\text { singular local } \\
\text { noun }\end{array}$} & The keys to the cabinet & $\begin{array}{l}\text { The keys to the ornate } \\
\text { Victorian cabinet }\end{array}$ \\
\hline & The labels on the bottle & $\begin{array}{l}\text { The labels on the tamper- } \\
\text { proof medicine bottle }\end{array}$ \\
\hline & $\begin{array}{l}\text { The boys that liked the } \\
\text { snake }\end{array}$ & $\begin{array}{l}\text { The boys that liked the } \\
\text { colorful garter snake }\end{array}$ \\
\hline & $\begin{array}{l}\text { The soldiers that the } \\
\text { officer accused }\end{array}$ & $\begin{array}{l}\text { The soldiers that the } \\
\text { battalion's senior officer } \\
\text { accused }\end{array}$ \\
\hline & \multicolumn{2}{|c|}{ Match (control) conditions } \\
\hline \multirow{4}{*}{$\begin{array}{l}\text { Singular subject, } \\
\text { singular local } \\
\text { noun }\end{array}$} & The key to the cabinet & $\begin{array}{l}\text { The key to the ornate } \\
\text { Victorian cabinet }\end{array}$ \\
\hline & The label on the bottle & $\begin{array}{l}\text { The label on the tamper- } \\
\text { proof medicine bottle }\end{array}$ \\
\hline & $\begin{array}{l}\text { The boy that liked the } \\
\text { snake }\end{array}$ & $\begin{array}{l}\text { The boy that liked the } \\
\text { colorful garter snake }\end{array}$ \\
\hline & $\begin{array}{l}\text { The soldier that the } \\
\text { officer accused }\end{array}$ & $\begin{array}{l}\text { The soldier that the } \\
\text { battalion's senior } \\
\text { officer accused }\end{array}$ \\
\hline \multirow[t]{4}{*}{$\begin{array}{l}\text { Plural subject, } \\
\text { plural local noun }\end{array}$} & The keys to the cabinets & $\begin{array}{l}\text { The keys to the ornate } \\
\text { Victorian cabinets }\end{array}$ \\
\hline & The labels on the bottles & $\begin{array}{c}\text { The labels on the tamper- } \\
\text { proof medicine bottles }\end{array}$ \\
\hline & $\begin{array}{l}\text { The boys that liked the } \\
\text { snakes }\end{array}$ & $\begin{array}{l}\text { The boys that liked the } \\
\text { colorful garter snakes }\end{array}$ \\
\hline & $\begin{array}{l}\text { The soldiers that the } \\
\text { officers accused }\end{array}$ & $\begin{array}{l}\text { The soldiers that the } \\
\text { battalion's senior } \\
\text { officers accused }\end{array}$ \\
\hline
\end{tabular}


be construed as distributed over the multiple objects mentioned in the prepositional phrase. Preambles such as the picture on the postcards and the label on the bottles are multiple-token items because their heads, though referring to a single abstract entity, require a token of that entity to occur on each of multiple objects in the concrete referent situation. To the extent that multiple-token items preferentially attract agreement "errors" (as in the picture on the postcards were .. .), it may be concluded that most agreement errors are errors only with respect to grammatical canons about number, not with respect to notional number.

\section{Method}

Participants. The participants were 40 Michigan State University undergraduates. They took part in the experiment to fulfill an extra-credit option in introductory psychology courses.

Materials. The basic materials for the sentence completion task consisted of the 32 sentence preambles shown in the Appendix. Half of the preambles had a prepositional phrase postmodifier after the head, and half had a subject- or object-relative clause postmodifier. Half of the prepositional phrase preambles were multiple token (items $1-8$ in the Appendix), and half were single token (items 9-16 in the Appendix), in the sense described above. Except for the four object relatives, the last word of the preamble was the local noun. In the object-relative fragments, the local noun was the penultimate word, immediately preceding the clausal verb.

Eight versions of each basic preamble were generated, corresponding to the eight conditions of the experiment. Half had short postmodifiers and half had long postmodifiers. The long postmodifiers were created by adding prenominal adjectives to the local noun. The adjectives lengthened each postmodifier by a median of 2 words (ranging from 2 to 4 ) or 5.5 syllables (ranging from 3 to 8 ). Within each length, one of the preambles had a singular head with a plural local noun, one had a plural head with a singular local noun, one had a singular head and local noun, and one had a plural head and local noun. The first two preamble types constituted the number-mismatch conditions, and the second two constituted their respective control conditions. Examples of the items are given in Table 1.

In addition to these preambles, 56 filler preambles were constructed. All were simple noun phrases (either determiner-noun or determiner-adjective-noun), half singular and half plural.

Eight 88-item lists were created from these materials. Every list contained 32 experimental preambles, one from each of the 32 sets, and all 56 fillers. Each experimental condition was represented by four experimental preambles on every list. Across the eight lists, every experimental preamble occurred just once.

Every list began with eight fillers. The arrangement of the remaining fillers and experimental items was random, with the constraint that no more than two experimental items could occur consecutively. The fillers occurred in the same locations across lists, as did experimental items from the same sets.

The lists were recorded on audio tape by a female speaker. The rate at which each preamble was produced during recording was kept as high as possible without compromising clarity. Listening to the preambles, the subjective impression is one of fast, clipped speech.

Procedure. The participants were run individually. They were told that they would hear a series of sentence beginnings, and that their task was to supply endings. No instructions 
were given about the forms of the completions, so the participants were free to complete them as they chose.

The experimenter presented the recorded preambles one at a time. After each one, the participant repeated it back as rapidly as possible along with its completion. If the participant indicated that he or she had failed to apprehend the preamble, the experimenter repeated it. The instructions emphasized rapid speech, and the experimenter encouraged the participants to talk faster after any trials on which their speech rate slowed appreciably. The experimental sessions were recorded on audio tape.

At the end of each session a speaking span test (adapted from Daneman \& Green, 1986) was administered. The test required subjects to compose a sensible, grammatical spoken sentence for each word in successively longer lists of words, one sentence per word. The test included 70 unrelated words, each two syllables long, with concreteness values greater than or equal to 5.00 and Thorndike-Lorge frequencies of $\mathrm{A}$ or AA in the Paivio, Yuille, and Madigan norms (1968). Each word was randomly assigned to one list in a set of 20 lists. The list set included five lists of each of four lengths ranging from two to five words.

The 20 lists were arranged in five cycles of four lists each. Each cycle included a two-, three-, four-, and five-word list, presented in progression. All the words in a single list were presented auditorily, one after another, and the participant had to maintain each one in memory until it was used in a sentence. After all the words in a list had been presented, the participant could begin to produce his or her sentences: The participants also received one practice cycle on a different group of words.

Scoring. The sentence completions were transcribed and then placed into one of four scoring categories, according to the following criteria. Correct responses were scored when participants repeated the preamble correctly, said it only once, produced an inflected verb at the very beginning of their completion, and appropriately used a verb form that differentiated plural from singular (all third-person present tense forms and the past tense forms of to be) in a complete sentence. ${ }^{5}$ In the rare cases when two different verb forms were produced in succession (as in a self-correction), only the first was scored. Agreement errors were scored when an utterance met all of the criteria for a correct response except that the verb form failed to agree in number with the subject of the sentence. Uninflected-verb responses likewise met all of the criteria for corrects, but included verb forms that did not differentiate singular from plural (although these verbs were often inflected for things other than number, we will refer to them simply as uninflected or uninflected-verb responses). Most of the remaining responses contained preamble reproduction errors, and were classified as miscellany.

Application of these criteria yielded 737 corrects (57.6\% of all responses), 63 agreement errors (4.9\%), 241 uninflected verbs (18.8\%), and 239 miscellaneous responses (18.7\%).

Design and data analyses. Each of the $\mathbf{4 0}$ participants received four preambles in all eight of the conditions formed by the orthogonal combinations of three factors. The factors included (1) the number of the local noun (singular versus plural), (2) the match in number between the head and the local noun (mismatch versus matched control), and (3) the length of the postmodifier containing the local noun (short versus long). Each of the 32 items occurred in every cell of the same design, presented to 5 participants.

The major statistical tests were performed using the numbers of agreement errors as the

${ }^{5}$ Most of the verbs used were past tense forms, reflecting what may be a general bias in English toward the past tense (Clark \& Stafford, 1969; Harris \& Brewer, 1973; Lapointe \& Dell, 1989; Svartvik, 1966). Because of this, our speakers' verbs tended to be neutral with respect to number unless they used a form of to be. Forms of to be therefore constituted a wide majority of the corrects and errors. 
dependent variable. Two analyses of variance were carried out, one with participants and another with items as random factors. All effects that achieved significance were reliable at or beyond the .05 level.

The relative proportions of errors among the correct and error responses (the responses containing agreement-marked verbs) are given in the figures, rather than the raw numbers, to facilitate comparisons across experiments. The raw numbers of errors are included in the tables.

\section{Results}

The proportions of agreement errors are shown in Fig. 1, and the raw numbers in Table 2. It is evident that the majority of the errors occurred in the mismatch condition (90.5\% overall), but there was no tendency for the length of the constituent containing the local noun to magnify this trend. Analyses of variance confirmed these impressions: There was a significant main effect of match condition $[F(1,39)=30.66$ with participants random; $F(1,31)=31.10$ with items random], and no interaction between agreement and length (both $F \mathrm{~s}<1$ ). The main effect of length was not reliable $[F(1,39)=1.71$ for participants; $F(1,31)=2.07$ for items].

The most revealing error pattern emerged in the disparity between singular and plural subjects in the mismatch condition. This is shown in Fig. 2 in terms of the net proportions of agreement errors in the four mismatch conditions. The net proportion equals the proportion of agreement errors that were committed in each mismatch condition minus the proportion of agreement errors committed in the corresponding control

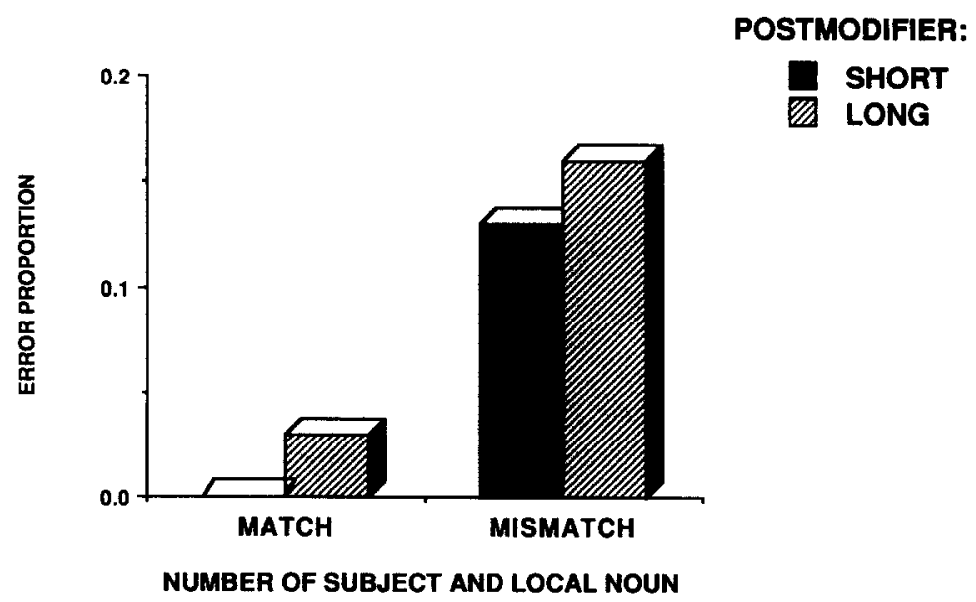

FIG. 1. Proportions of agreement errors associated with number-matching or numbermismatching subjects and local nouns. The short and long conditions differed in the length of the postmodifiers in the sentence preambles that the speakers completed. 
TABLE 2

Numbers of Agreement Errors in Experiment 1

\begin{tabular}{ccc}
\hline & \multicolumn{3}{c}{ Plurality of subject } \\
\cline { 2 - 3 } Length of preamble & Singular & Plural \\
\hline \multirow{3}{*}{ Short } & 25 & Number mismatch \\
Long & 25 & 3 \\
& \multicolumn{2}{c}{ Number match (control) } \\
Short & 0 & 0 \\
Long & 2 & 4 \\
\hline
\end{tabular}

condition (so errors occurring after preambles with singular heads and plural local nouns were adjusted according to the errors occurring after singular heads with singular local nouns, and so on). The subtraction yields a better estimate of true agreement errors, corrected for dialect factors and random mistakes. Figure 2 indicates that agreement problems were by and large restricted to the conditions in which the head was singular and the local noun plural. In the analyses of variance, the statistical diagnostics of this pattern included a significant main effect of subject number, with more singular than plural errors $[F(1,39)=19.13$ with participants random; $F(1,31)=14.62$ with items random], and a significant interaction between number and mismatch, attributable to the fact that the pattern appeared only in the mismatch conditions and not in the

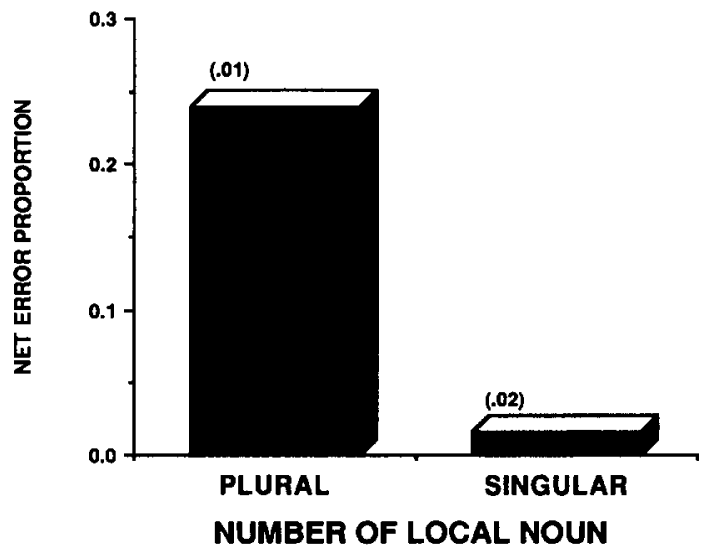

Fig. 2. The net proportions of agreement errors after singular and plural local nouns in Experiment 1. The net proportion represents the proportion of errors in each mismatch condition (where the subject and local nouns mismatched in plurality) minus the proportion in the corresponding control condition (where the subject and local nouns matched in plurality). Error proportions in the control conditions are shown in parentheses. 
control conditions $[F(1,39)=24.32$ with participants random; $F(1,31)=$ 13.07 with items random].

The numbers of uninflected-verb responses in the various length and plurality conditions are shown in Table 3 . These are the responses that included verb forms that were undifferentiated with respect to the plurality of the subject. Fewer such forms were used when the subject was plural and separated from the verb by a long constituent. In analyses of variance, this produced a significant main effect of length $[F(1,39)=4.85$ with participants random; $F(1,31)=5.06$ with items random] qualified by a significant interaction between length and number $[F(1,39)=6.41$ with participants random; $F(1,31)=8.56$ with items random].

Examination of the miscellaneous response category revealed a large effect of the lengths of the preambles, with $74 \%$ of the 239 responses occurring in the long-preamble conditions. This was the only effect that achieved significance in analyses of variance for this category $[F(1,39)=$ 51.09 with participants random; $F(1,31)=25.54$ with items random]. Because responses fell into this category when participants failed to correctly repeat the preamble, the length effect indicates more difficulty repeating longer than shorter fragments.

A partitioning of agreement errors according to the type of constituent that followed the head noun phrase (either prepositional phrase or relative clause) revealed more errors after prepositional phrases: $68 \%$ of the subject-verb agreement errors occurred after phrases rather than clauses. This difference was significant in a comparison of errors on phrase versus clause items [two-tailed $t(30)=2.45$ ]. When errors in the mismatch conditions alone were included in this comparison, the difference between phrases and clauses actually increased slightly, with $72 \%$ of the errors occurring after phrases. Errors after subject-relative clauses were more common than errors after object-relative clauses (averaging 1.17 errors per subject-relative item versus .5 errors per object-relative item in the mismatch conditions), though this difference failed to achieve significance because of the small numbers of items involved.

There were virtually no differences in the distributions of errors for the single- versus multiple-token preambles. The numbers of errors across conditions are shown in Table 4 . These errors were roughly equally divided between the short and long preamble conditions.

TABLE 3

Numbers of Uninflected Responses in Experiment 1

\begin{tabular}{ccc}
\hline Length of preamble & Singular & Plural \\
\hline Short & 65 & 73 \\
Long & 65 & 36 \\
\hline
\end{tabular}


TABLE 4

Numbers of Agreement Errors for Single- and Multiple-Token Items in Experiment 1

\begin{tabular}{lccc}
\hline & \multicolumn{3}{c}{ Plurality of subject } \\
\cline { 2 - 4 } \multicolumn{1}{c}{ Item type } & Singular & Plural \\
\hline Single token & 18 & Number mismatch & 2 \\
Multiple token & 19 & & 2 \\
Single token & & Number match (control) & \\
Multiple token & 0 & & 0 \\
\hline
\end{tabular}

Performance on the speaking span test was evaluated by counting the number of sentences that the participants successfully produced (this is the total performance measure described by Daneman and Green, 1986). Successful production required that a sentence be grammatical and contain one of the target words from the immediately preceding word set. If more than one sentence was produced for a given target word, only one of the sentences received credit. Similarly, if a single sentence contained more than one target word, credit was given for only one.

The mean of the total performance scores on the speaking span test was 54.8 , with a standard deviation of 4.8 and a range from 47 to 66 . Correlations were calculated between the participants' total performance scores and two other measures: (a) The proportion of correct agreements relative to the total number of agrcement-making verbs that the participants produced in the mismatch conditions of the experiment (this represents correct agreement as a proportion of the total of correct and erroneous agreements); and (b) the number of preamble repetition errors they produced. The correlation between speaking span and proportion of correct agreements was a negligible .05 ; the correlation between speaking span and preamble repetition errors was larger and significant, with an $r$ of $-.46[t(38)=3.19]$.

\section{Discussion}

The results for agreement errors disclosed three important things. First, errors were most likely when a nominal postmodifier (with a local noun) separated the head noun from the verb, and the number of the local noun differed from that of the head. Second, there was a marked asymmetry in the distributions of these errors, with errors being much more likely when the head was singular and the local noun plural than when the head was plural and the local noun singular. Finally, the occurrence of agreement errors was unaffected by the length of the postmodifier, with errors being 
just as likely with short postmodifiers as with long ones. We will discuss these results in turn.

The increase in agreement errors following a mismatching local noun is in line with the pattern noted for the same kinds of errors in spontaneous speech: People seem to be prone to say such things as The bridge to the islands were crowded. But this rarely occurred when the head was plural and the local noun was singular: The speakers seldom made the mistake found in The bridges to the island was crowded. Instead, agreement errors were largely confined to the conditions in which the head was singular and the local noun was plural. This is in line with a similar bias in spontaneous errors in speech and writing which, as we noted in the introduction, was $83 \%$ across three sets of errors available to us. In the present experiment, $88 \%$ of the errors in the mismatch conditions occurred with a singular head and a plural local noun.

This pattern tells us that these agreement errors are probably not due to a failure to correctly identify the subject of the sentence. We know from the work of MacWhinney and Bates (Bates et al., 1982; MacWhinney et al., 1984) that there is a strong tendency for English speakers to identify preverbal nouns as subjects, and one possible explanation for agreement errors would be that the preverbal noun preempts the subject role. Had that happened consistently, errors would have been as common for singular as for plural local nouns. They were not.

There is, however, a possible trivial explanation for the asymmetry in the experimentally elicited errors. Suppose that the participants routinely heard and in place of on in the label on the bottles or the labels on the bottle, and our transcriber routinely failed to hear the substitution when they repeated the preambles. This would lead to a systematic overestimation of plural verb errors, since The label and the bottles are is correct, but would be classified as an error under this scenario, while The labels and the bottle are is also correct, and would be correctly classified. We think this and other perception-based doubts about the data are unfounded, for two reasons. Most importantly, the control conditions created comparable occasions for misperception, without yielding similar error patterns. So, singular number-matched items (such as The label on the bottle) should also have led to many cases of misclassification (from reproductions such as The label and the bottle are), but did not: Only 2 errors were recorded in the singular-match condition, compared to 50 in the singular-mismatch condition. Second, there were no detectable disparities between those items with prepositions that might readily be heard as and (in and on) and those items with prepositions that do not readily lend themselves to this misperception ( $t o$ and from).

The apparent restriction of the error pattern to plural local nouns weakens the credibility of various explanations that attempt to assimilate this 
sort of agreement to various rule-governed accounts in which the local noun is granted a general license to control agreement, regardless of its number. Among these is the reference-based hypothesis, which would seem to predict that both the picture on the postcards and the pictures on the postcard could lead to errors because of the disparity in number between the head noun and the entity hypothesized to ground or fix the reference of the entire phrase, the referent of the local noun.

The reference-based hypothesis encounters an even more serious problem in the finding that the notional or referential correlate of number that was varied in this experiment had surprisingly little relation to the occurrence of errors. This variation involved the contrast between items such as The bridge to the islands and The picture on the postcards. To validate our a priori classification of the items, we gave the versions of the items with singular heads and plural local nouns to 11 naive raters. The raters were provided with a description and example of the distinction, and were asked to indicate for each preamble whether it referred to a single object or multiple objects of the same type. Across all the raters, the mean proportion of multiple-object judgments for the eight single-token items was .18 , with a range from .09 to .27 , while the mean proportion of multiple-object judgments for the eight multiple-token items was .79 , with a range from .64 to .91 . We also correlated the numbers of agreement errors for those preambles with singular heads and plural local nouns with their judged multipleness, obtaining an $r$ of -.04 . Finally, we simply counted the numbers of errors for the five items with the highest (greater than .82) and lowest (less than .18) ratings of multipleness. There were 9 and 5 , respectively, thereby tending in the opposite direction from what we would expect were these not so much errors as reflections of number in the situation denoted by the preamble.

The other notable feature of the results was the absence of any effect on agreement errors of the length of the postmodifier. Errors constituted only $17 \%$ of the marked verb responses in the mismatch conditions, conditions designed to elicit such errors, and were just as rare under circumstances that clearly stretched the limits of immediate memory (preamble repetition errors were nearly three times more likely in the long preamble than in the short preamble conditions, but agreement errors were no more likely). The results from the speaking span test further suggest that memory failures played relatively little part in creating the errors. Finally, in light of the difficulty people have in remembering material beyond the most recent clause (Caplan, 1972; Jarvella, 1971), we might have expected more errors for itcms with clausal rather than phrasal postmodifiers. Yet phrasal postmodifiers produced reliably more errors. Although the heads and local nouns of the compared items were not equated in the present 
experiment, this result has been replicated when they were (Bock \& Cutting, 1990).

Uninflected verb forms. An analysis of the verb forms that were uninflected for number yielded one clear finding. Fewer such forms were used with plural subjects that had long postmodifiers, regardless of match or mismatch. One possible explanation of this pattern has to do with the semantic richness of number-neutral past-tense verbs, coupled with the semantic complexity of the conditions in which they failed to appear. Number-neutral past-tense verbs are by and large lexical verbs (ran, created, exploded, etc.), so called because they are semantically more differentiated than to be (the various form of which constituted the most common agreement-marked verbs in the experiment). As a result, their use is much more constrained by the features of their potential arguments than is a verb such as to be. Anything that further constrains this relationship may incline a speaker toward a less selective verb form, and plurality coupled with substantial postmodification may have contributed to this inclination in tandem. Alternatively, the sheer overall complexity of the long plural subjects may have promoted the use of the short, simple forms of be. That such forms require marking for number does not seem to add to their complexity.

Preamble repetition errors. As noted above, preamble repetition errors increased when the preambles were long. In addition, the occurrence of preamble repetition errors was negatively correlated with scores on a speaking span test. These results indicate that the long preambles created a substantial memory or processing burden, one large enough to reflect individual differences in processing ability. Yet the length of the preamble did not impair agreement, and agreement errors were not associated with speaking span. This gives further credence to the claim that the sheer distance between the subject and verb is of little consequence for the agreement process.

\section{EXPERIMENT 2}

The results of the first experiment help to establish that agreement errors can be elicited under experimental conditions, that the errors so elicited bear interesting qualitative and quantitative similarities to spontaneously produced errors, and that the observed agreement pattern is probably not just an alternative, denotatively principled construal of the number denoted by the subject noun phrase. However, it does not establish whether the widely acknowledged conceptual correlates of subjecthood might be more successful in leading the agreement operation astray. If local nouns are merely much less likely than head nouns to have such conceptual features of subjects as animacy, these influences could easily 
be hidden in the natural errors as well as in our elicited errors. To explore this possibility, we conducted a second experiment that systematically varied this core conceptual marker of subjecthood.

The experiment also varied the rated concreteness of the items' subject and local nouns. Although the reference-based hypothesis examined in the first experiment fared poorly, there is a related way of interpreting it in terms of the relative definiteness, specificity, or sheer palpability of the referent of the local noun. According to this idea, the number of a relatively concrete local noun may hold more sway over the judged number of an abstract subject (as in the speech of the authors) than a relatively abstract local noun does over the judged number of a concrete subject (as in the mountain of the nomads). Any such effect could be heightened by the relationship between subjecthood and definiteness/specificity/concreteness (Bock \& Warren, 1985; Clark \& Begun, 1971; James, Thompson, \& Baldwin, 1973; Ransom, 1977).

\section{Method}

Participants. The participants were 64 members of the Michigan State University community, recruited via an advertisement in the campus newspaper. They earned three dollars apiece for serving in the half-hour experiment.

Materials. The primary experimental materials consisted of 32 sentence-preamble items, each of which contained a head noun phrase followed by a prepositional phrase that contained the local noun phrase. There were eight versions of each item. In the four versions making up the inanimate local-noun condition, the head noun phrase was animate and the local noun phrase inanimate (e.g., the girl on the blanket). The remaining four versions of each item constituted the animate local-noun condition. In these, the same noun phrases were reversed to create an inanimate head with an animate local noun (e.g., the blanket on the girl). Half of the items in each of these conditions had heads and local nouns that differed in number (singular head and plural local noun, and vice versa; these comprised the mismatch condition), and half had heads and local nouns that matched in number (these again comprised the control condition). Examples of items in each mismatch condition are given in Table 5 .

The words used as the heads and local nouns were balanced for relative concreteness. In half of the items, the animate head nouns in their singular forms were normatively more concrete than the inanimate local nouns, and in the other half, less concrete. To create the items, pairs of animate and inanimate nouns were selected from one of four sets of concreteness norms (Gilhooly \& Logie, 1980a,b; Paivio et al., 1968; Spreen \& Schulz, 1966). Both words for a given item came from the same norms. The mean concreteness difference between the heads and local nouns in the high-concrete items was +.67 , with a standard deviation of .40 . The range was from +1.33 to +.04 . The mean concreteness difference between the heads and local nouns in the low-concrete items was -.67 , with a standard deviation of .35 . The range was from -1.28 to -.04 .

Eight experimental lists were created and recorded following the guidelines described for the lists in the first experiment. Each list contained a total of 88 items, including 56 fillers like those in Experiment 1. Every experimental condition was represented by two items on each list.

Procedure. The procedure outlined for Experiment 1 was also followed in this experiment. 
TABLE 5

Examples of Sentence Preambles in the Animacy and Mismatch Conditions of Experiment 2

\begin{tabular}{|c|c|c|}
\hline \multirow{2}{*}{$\begin{array}{l}\text { Mismatch } \\
\text { condition }\end{array}$} & \multicolumn{2}{|c|}{ Animacy condition } \\
\hline & Inanimate local noun & Animate local noun \\
\hline $\begin{array}{l}\text { Singular subject, } \\
\text { plural local noun }\end{array}$ & $\begin{array}{l}\text { High-concrete subject } \\
\text { The author of the } \\
\text { speeches }\end{array}$ & $\begin{array}{l}\text { Low-concrete subject } \\
\text { The speech of the authors }\end{array}$ \\
\hline $\begin{array}{l}\text { Plural subject, } \\
\text { singular local } \\
\text { noun }\end{array}$ & The authors of the speech & $\begin{array}{l}\text { The speeches of the } \\
\text { author }\end{array}$ \\
\hline $\begin{array}{l}\text { Singular subject, } \\
\text { plural local noun }\end{array}$ & $\begin{array}{l}\text { Low-concrete subject } \\
\text { The nomad of the } \\
\text { mountains }\end{array}$ & $\begin{array}{l}\text { High-concrete subject } \\
\text { The mountain of the } \\
\text { nomads }\end{array}$ \\
\hline $\begin{array}{l}\text { Plural subject, } \\
\text { singular local } \\
\text { noun }\end{array}$ & $\begin{array}{l}\text { The nomads of the } \\
\text { mountain }\end{array}$ & $\begin{array}{l}\text { The mountains of the } \\
\text { nomad }\end{array}$ \\
\hline
\end{tabular}

Scoring. The scoring categories developed for the first experiment were used again, and yiclded the following response distribution: 1236 corrects ( $60.4 \%$ of all responses), 48 agreement errors (2.3\%), 623 uninflected verbs (30.4\%), and 141 miscellaneous responses (6.9\%).

Design and data analyses. Each of the 64 participants received two preambles in each of eight conditions. The eight conditions were formed by the orthogonal combinations of three factors: (1) the number of the local noun (singular versus plural), (2) the match in number between the head noun and the local noun (match versus mismatch), and (3) the animacy of the local noun (animate versus inanimate). The design for items was the same, with each of the items administered to eight subjects in each condition.

The major statistical tests again were performed with the numbers of agreement errors as the dependent variable. Two analyses of variance were carried out, one with participants and another with items as random factors. All effects that achieved significance were reliable at or beyond the .05 level.

\section{Results}

Figure 3 shows the net proportions of agreement errors in the mismatch conditions, after subtracting the errors from the corresponding control conditions (control condition proportions are given in parentheses). The figure reveals that errors were again confined to preambles with plural local nouns, but were unaffected by the animacy of the local nouns. Table 6 gives the raw numbers of crrors, and reveals the same pattern.

Analyses of variance on the numbers of errors in all conditions produced a significant main effect of mismatch $[F(1,63)=11.2$ for participants; $F(1,31)=10.4$ for items], with more errors in the mismatch condition than in the control condition. The predominance of errors after plural local nouns produced a significant interaction between mismatch and plurality $[F(1,63)=17.1$ for participants; $F(1,31)=14.6$ for items $]$. 


\section{EXPERIMENT 2}

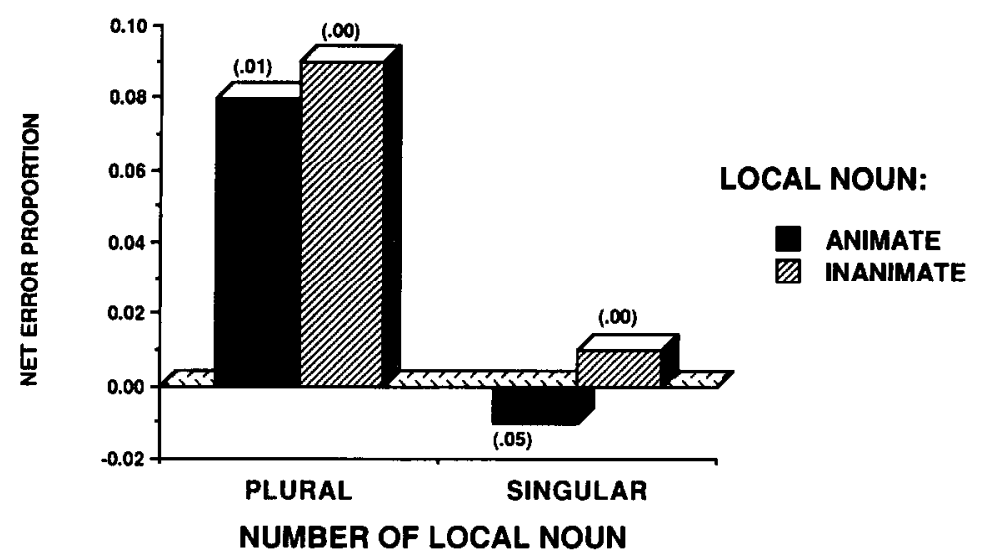

REPLICATION

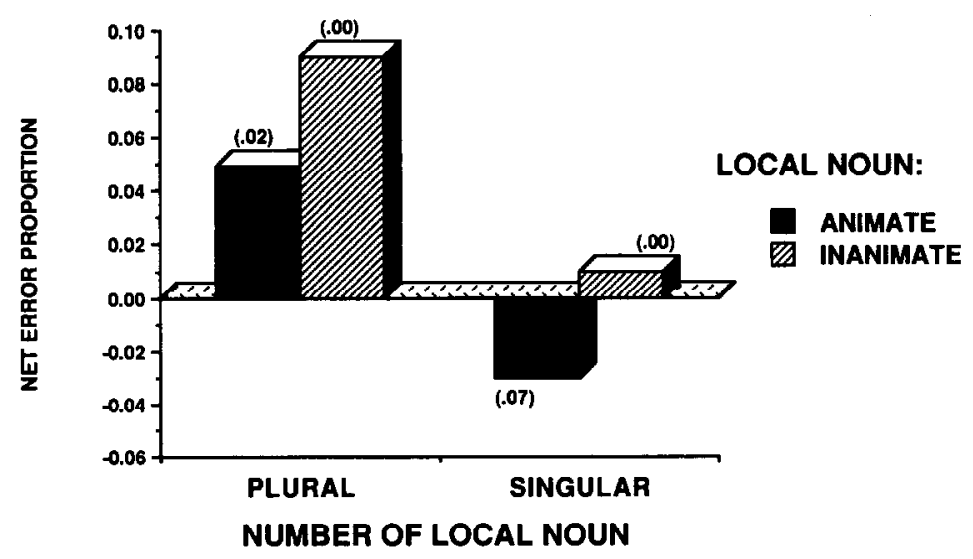

FIG. 3. The net proportions of agreement errors after singular and plural animate and inanimate local nouns in Experiment 2 (top panel) and the replication (bottom panel). Error proportions in the control conditions are shown in parentheses.

There was also a significant main effect for animacy $[F(1,63)=9.9$ for participants; $F(1,31)=4.2$ for items]. This is attributable to the fact that there were more errors after animate local nouns regardless of whether they matched or mismatched the head in number. The explanation for this became clear when we examined the frequency of uninflected verb responses, which are shown in Table 7. Uninflected verbs were uniformly much commoner after inanimate than after animate local nouns $[F(1,63)$ 
TABLE 6

Numbers of Agreement Errors in Experiment 2

\begin{tabular}{lrcr}
\hline & \multicolumn{2}{c}{$\begin{array}{c}\text { Number match between subject } \\
\text { and local noun }\end{array}$} \\
\cline { 2 - 4 } $\begin{array}{c}\text { Animacy and number } \\
\text { of mismatch local noun }\end{array}$ & \multicolumn{2}{c}{ Mismatch } & Experiment 2 \\
\hline & 1 & & 0 \\
Inanimate singular & 13 & & 0 \\
Inanimate plural & 7 & & 10 \\
Animate singular & 16 & & 1 \\
Animate plural & & Replication & \\
& 1 & & 0 \\
Inanimate singular & 13 & & 0 \\
Inanimate plural & 7 & & 13 \\
Animate singular & 12 & & 3 \\
Animate plural & & & \\
\hline
\end{tabular}

$=33.3$ for participants; $F(1,31)=15.0$ for items]. The reason may be found once again in the vocabulary of English: There are many more lexical verbs that take animate than inanimate subjects (Jarvella \& Sinnott, 1972). Since the head was inanimate when the local noun was animate, a proper verb for that subject could less often be found among the lexical verbs. Speakers therefore used the copula (be) morc often, creating more opportunities for agreement errors to arise in both the mismatch and control conditions after preambles with inanimate subjects.

Analyses of the preamble repetition errors revealed two broad trends. Overall, there were more repetition errors when the head and local nouns mismatched in number than when they matched ( 83 to 58 ), and when the subject was plural than when it was singular ( 86 to 55). The first of these effects reflects an occasional switch of the plural morpheme between the two noun phrases in the preambles (this was significant for participants

TABLE 7

Numbers of Responses with Verbs Uninflected for Number in Experiment 2

\begin{tabular}{lccc}
\hline \multirow{2}{*}{$\begin{array}{c}\text { Animacy of } \\
\text { mismatch local noun }\end{array}$} & \multicolumn{2}{c}{ Plurality of subject and local noun } \\
\cline { 2 - 3 } & Match & Mismatch \\
\hline Inanimate & 194 & & 197 \\
Animate & 112 & & 120 \\
& & Replication & 198 \\
Inanimate & 177 & & 114 \\
Animate & 96 & & \\
\hline
\end{tabular}


but not for items; $F(1,63)=4.8 ; F(1,31)=3.3)$; the second was due to a tendency to add and subtract plurals on the local noun when the head was plural, more so than when it was singular (this was significant for both participants and items; $F(1,63)=9.3 ; F(1,31)=7.3)$. No other effects were reliable.

A breakdown of agreement errors for items with concrete versus abstract local nouns yielded the pattern shown in the top panel of Fig. 4. The

\section{EXPERIMENT 2}

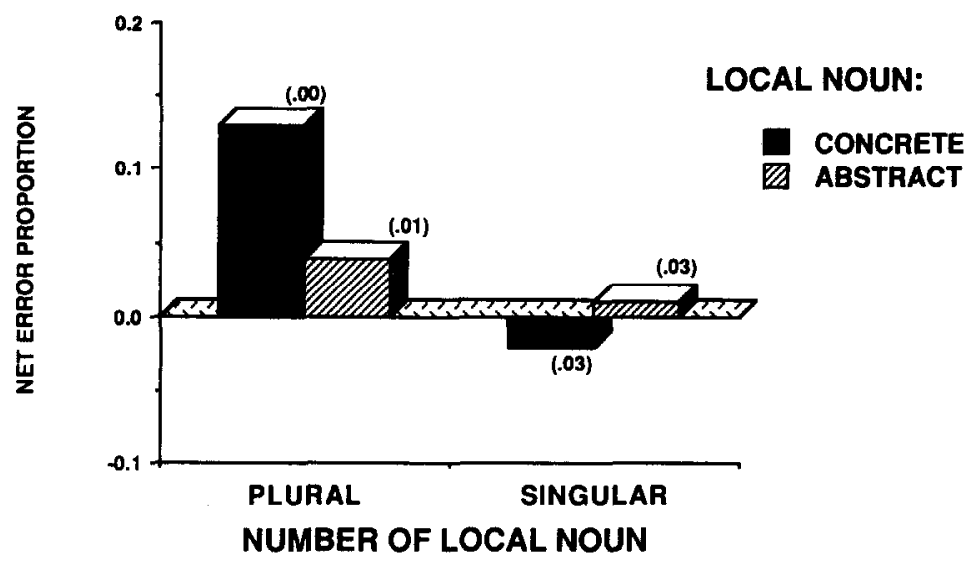

REPLICATION

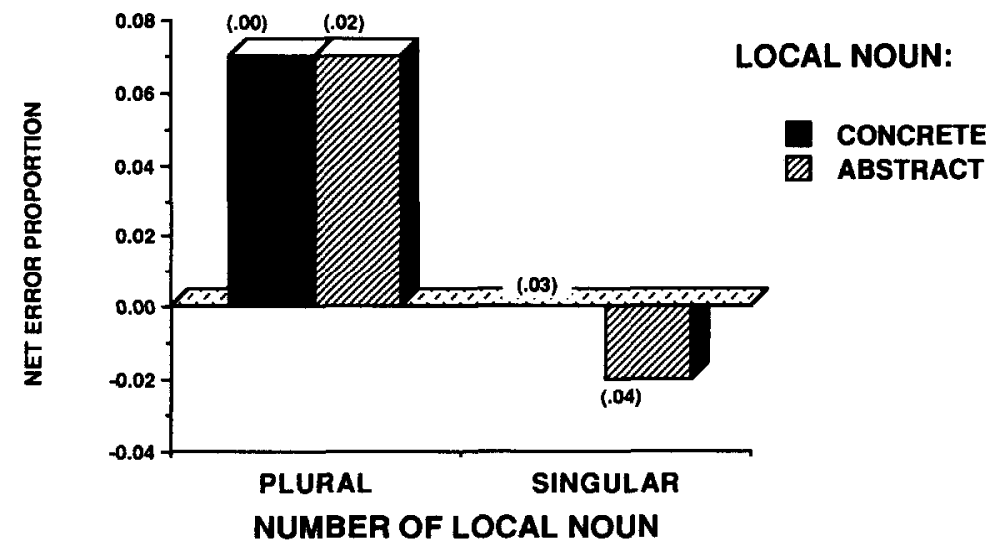

Fig. 4. The net proportions of agreement errors after singular and plural concrete and abstract local nouns in Experiment 2 (top panel) and the replication (bottom panel). Error proportions in the corresponding control conditions are in parentheses. 
singular-plural asymmetry was again in evidence, but more prominently for concrete than for abstract local nouns. Incomplete counterbalancing of concreteness across lists prevented a straightforward statistical evaluation of this effect for participants. An analysis was performed for the items, including the factors of mismatch, plurality, and concreteness. In addition to the overall mismatch effect, the analysis indicated that concrete local nouns were marginally more likely than abstract local nouns to create agreement errors when they were plural $[F(1,31)=3.8, p<.06$, for the interaction between concreteness and number], but only when they mismatched the head in number $[F(1,31)=3.6, p<.07$, for the three-way interaction]. Animacy was excluded from this analysis because its two levels were nested in the interaction of items and concreteness, but inspection revealed the same concreteness effects for both animate and inanimate local nouns.

\section{Discussion}

It appears that the agreement process is not easily misled by the animacy of the local noun. Relative to the control conditions, the frequency of errors for animate and inanimate local nouns was about the same. Moreover, the singular-plural asymmetry was identical for animate and for inanimate local nouns. Plural local nouns elicited errors, both when they were animate and when they were inanimate; singular local nouns did not, regardless of whether they were animate or inanimate. Local animacy did not affect agreement, but local plurality did.

Animacy was, however, associated with the kinds of verbs that the speakers employed in their completions. Because animate subjects can be used with a wider range of lexical verbs than inanimate subjects, and because lexical verbs are uninflected for number in the past tense, the speakers produced more uninflected verbs after animate than after inanimate subjects (with inanimate and animate local nouns, respectively). Two side effects of this were (a) that the copula (which is inflected for number in the past tense) was used more often as the verb for inanimate subjects, and therefore occurred more often after animate local nouns, and (b) that the number of opportunities for agreement errors therefore increased after animate local nouns. The increase in the number of agreement errors after animate local nouns cannot be attributed to mistaken agreement with the local noun because the same increase in errors occurred in the control condition. In the control condition, such errors took the form of completions such as The colonies of the kings was rebellious. The presenting problem, obviously, is neither mistaken agreement with the local noun nor number confusion created by the local noun, but a more-or-less random error of verb form. Taking this factor into account, 
number errors were actually slightly less common after animate than after inanimate local nouns.

The error pattern for concrete local nouns was interestingly different from that for animate local nouns. In an attempt to replicate it, we repeated Experiment 2 with a different sample of 64 participants, all of them Michigan State University undergraduates whose service in the experiment earned them extra credits in introductory psychology courses. They received the same items as in Experiment 2, but the items were assigned to lists in a manner that counterbalanced both animacy and concreteness for individual participants.

The replication yielded 1292 corrects ( $63.1 \%$ of all responses), 49 agreement errors (2.4\%), 585 uninflected verbs $(28.6 \%)$, and 120 miscellaneous responses (5.9\%). The lower panels of Fig. 3 and Tables 6 and 7 reveal patterns of effects for number mismatches, plurality, and animacy comparable to those of the main experiment. The net number of agreement errors was smaller after animate than after inanimate local nouns. However, the lower panel of Fig. 4 shows that the concreteness difference disappeared: Errors were about equally likely after concrete and abstract local nouns.

It seems that the concreteness effects in Experiment 2 were probably artifacts of the unbalanced distribution of concreteness variations over participants. However, it is important to point out that even if the results of the replication are aberrant, and concrete local nouns are associated with increased agreement errors, this cannot be explained as a tendency for the verb to agree with a concrete noun. Figure 4 reveals no tendency for singular local nouns to create number disagreements, whether they were concrete or abstract.

\section{EXPERIMENT 3}

The absence of any direct effect of animacy on agreement errors suggests that information about animacy is irrelevant to the usual implementation of subject-verb agreement. To reconcile these results with the irrefutable evidence that animacy and subjecthood are closely associated, it might be argued that agreement, in terms of language performance, is mischaracterized: Perhaps it operates not with respect to the structure of the sentence, but with respect to any preverbal plural. To take care of the fact that there were, objectively, few agreement errors even when the head was singular and the local noun was plural, we might add the proviso that, if the first noun is singular, plural-verb selection does not apply. Under this construal, structural relations are simply irrelevant to the agreement process, and the only thing that matters is plurality and sentence position. 
However ad hoc such a description of agreement might seem, in frameworks that ignore structural and symbolic relationships, plurality and position may be regarded as the only information to which a processing mechanism has access. It is therefore reasonable to determine whether this account has any validity. Experiment 3 was designed to do this.

The experiment capitalized on the existence in English of constructions in which the second of two preverbal noun phrases is the subject of the first verb produced. In sentences with subject-relative clauses (e.g., The king that the colonies oppose is a tyrant) there are two noun-phrase subjects, the main-clause or upstairs subject (the king), and the relativeclause or downstairs subject (the colonies). The first verb produced (oppose) is the verb or the relative clause, which should agree with the downstairs and not the upstairs subject (so The king that the colonies opposes is a tyrant is unacceptable). However, if the plural-positional description of agreement accurately captures normal performance, such unacceptability should be the norm in actual speech, producing the same pattern of verb responses as in the previous experiment. Accordingly, the verb of the relative clause should actually agree with the upstairs rather than the downstairs subject, in alignment with the correct responses in the previous experiments. On the plural-positional hypothesis, these should constitute the majority of the agreement-marking responses.

But if the subject relation plays a necessary role in verb agreement, the modal response patterns should reverse in the present experiment, relative to the previous ones. That is, there should be relatively few cases of disagreement with local nouns (downstairs subjects), with syntactically correct agreement patterns predominating. For this to occur, the agreement operation must reliably link the first verb to its own subject, the immediately preceding noun phrase, and not to the first noun phrase.

Experiment 3 had a second purpose, again concerned with conceptual influences on agreement errors. Experiment 2 and its replication made the case that animacy does not routinely affect subject-verb agreement; verbs agree (or fail to agree) with subjects, not with animate or inanimate noun phrases. The sentence preambles used in Experiment 3 allowed us to explore the role of animacy in a situation in which subject-verb agreement was complicated by the presence of two arguments that both bore the subject relation, and presented a real problem in designating one of them as the subject of the lower clause.

The difficulty arises specifically when the upstairs subject is animate and the downstairs subject is inanimate, as in The politician that the flag. Completing this preamble requires a formulation in which the upstairs subject serves not only as the subject of the higher clause but as the logical object of the verb in the lower clause (as in The politician that the flag adorned was pleased with his reception). This in turn requires a 
lower-clause verb that can take an inanimate entity as its subject, and an animate one as its direct object. Because languages are organized in such a way that few such predicates exist (perhaps reflecting the characteristics of human knowledge; see Keil, 1979), the would-be speaker confronts a potential impasse. One solution is to reinterpret the relation between the two subjects, so that the mental representation of the preamble is analogous to The flag that the politician. This reinterpretation allows the animate subject to control the verb in the lower clause, and eases the predication problem.

This situation should elicit agreement errors (defined with respect to standard canons of grammaticality) that reflect genuine subject identification mishaps. When the numbers of the subjects differ, as in The politicians that the flag, an agreement error will ensue when the verb in the lower clause agrees with the upstairs and not the downstairs subject (The politicians that the flag were ...). So, if differences in animacy prompt covert reassignment of the subject relation, and thereby affect the agreement process, more agreement errors on the verb in the lower clause should occur when the upstairs subject is animate than when it is inanimate.

\section{Method}

Participants. The participants were 64 Michigan State University undergraduates, taking part in return for extra credit in introductory psychology classes. None of them had been in previous experiments.

Materials. The items from Experiment 2 were modified so that the relativizer that replaced the preposition in each experimental preamble. In the mismatch conditions this yielded preambles such as The songs that the composer and The song that the composers (the local noun is an animate downstairs subject) and The composers that the song and The composer that the songs (the local noun is an inanimate downstairs subject). In all other respects the items were the same as those in the second experiment. The lists were identical to the ones used in the replication of Experiment 2, except for the change in the preambles themselves.

Procedure. The procedure duplicated that of the preceding experiments.

Scoring. The form of the first verb produced (the verb in the relative clause) was scored using the criteria described in Experiment 1, except that the requirement that the participant produce a complete sentence was relaxed to admit production of a least one complete clause. Keeping in mind that the verb forms that were correct in the previous experiments (reflecting the number of the first noun phrase) are errors here, and the responses that were considered errors (reflecting the number of the second noun phrase) are correct, the distribution of scores was as follows: 516 corrects ( $25.2 \%$ of all responses), 37 errors ( $1.8 \%$ of all responses), 1168 uninflected verbs (57.0\%), and 327 miscellaneous responses (16.0\%).

Design and data analyses. The design and analyses were like those of Experiment 2.

\section{Results}

Verb forms that agreed with the number of the local noun constituted .93 of all responses with inflected verbs in the present experiment. In 
comparison, the proportion of such responses in Experiment 2 was .04 . The obvious reason is that these verb forms were correct with respect to the local nouns in the present experiment, since the local nouns were the structurally defined subjects of the downstairs clauses.

Figure 5 gives the net proportions of agreement errors following animate and inanimate upstairs subjects. All effects were significant (the smallest $F$ s were those for the interaction between animacy, number, and mismatch; $F(1,63)=6.2$ for participants and $F(1,31)=6.8$ for items). The results can be easily summarized: Agreement errors were more likely following animate than inanimate upstairs subjects, and following plural than singular upstairs subjects, and when the upstairs subject mismatched the local subject in number. Relative to the other conditions, errors were most common after animate plural upstairs subjects that mismatched the local subject. The same patterns can be seen in the raw errors in Table 8.

The uninflected verb responses were very similar to those of the preceding experiments, when the nature of the verb's actual subject is taken into account. Uninflected verbs followed animate local subjects more often than inanimate ones $[F(1,63)=267.8$ for participants; $F(1,31)=$ 212.4 for items]. There was also a tendency for more uninflected verbs to occur in the control conditions $[F(1,63)=5.4$ for participants; $F(1,31)=$ 7.0 for items], most clearly after plural downstairs subjects (the interaction between mismatch and number was significant for participants $[F(1,63)=5.3]$ but marginal for items $[F(1,31)=3.0, p<.1)$. Table 9 gives the numbers of uninflected verbs in the various conditions.

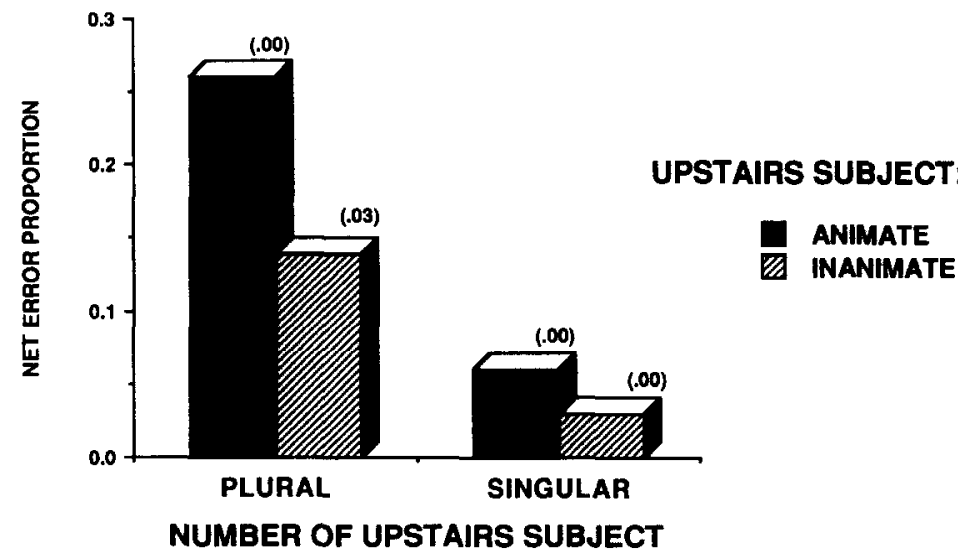

FIG. 5. The net proportions of agreement errors associated with singular and plural animate and inanimate upstairs subjects (subjects in the higher clause) in Experiment 3. The verbs were produced after preambles such as The colonies that the king . . . , where the upstairs subject is colonies. Error proportions in the corresponding control conditions are in parentheses. 
TABLE 8

Numbers of Agreement Errors in Experiment 3

\begin{tabular}{lcc}
\hline \multirow{2}{*}{$\begin{array}{c}\text { Animacy and number } \\
\text { of mismatch } \\
\text { upstairs subject }\end{array}$} & \multicolumn{2}{c}{$\begin{array}{c}\text { Number match between upstairs } \\
\text { and downstairs subject }\end{array}$} \\
\cline { 2 - 3 } & Mismatch & Match \\
\hline Inanimate singular & 1 & 0 \\
Inanimate plural & 4 & 1 \\
Animatc singular & 6 & 0 \\
Animate plural & 25 & 0 \\
\hline
\end{tabular}

Preamble reproduction errors occurred more often in the mismatch conditions than in the control conditions $[205$ to $122 ; F(1,63)=23.9$ for participants; $F(1,31)=22.0$ for items], and more often when the downstairs subject was inanimate than when it was animate $[245$ to $82 ; F(1,63)$ $=39.9$ for participants and $F(1,31)=66.9$ for items]. The first again reflects a tendency to change the numbers of the two noun phrases; the second reflects the complexity of preambles such as The author that the speech ... Our speakers often substituted prepositions for the relative pronoun, or repeated the preamble, probably because they had trouble dealing with the intended relation.

Examination of the net agreement errors associated with plural upstairs subjects revealed slightly but insignificantly more errors when they were concrete than when they were abstract (16 to 12$)$. For singular upstairs subjects, 3 errors occurred when they were concrete, and 4 when they were abstract.

Second verbs. We also examined response patterns for the second verbs produced, the verbs in the higher clause. Relative to the number of the upstairs subject, there were 1227 correct responses $(59.9 \%$ of all responses), 113 errors (5.5\%), 238 uninflected verbs (11.6\%), and 470 miscellaneous responses $(23.0 \%)$. Because we had no control over the contents of the participants' continuations, these verbs were produced under a wider range of influences than the first verbs. However, the general trends were sensible and very similar to the results for the second exper-

TABLE 9

Numbers of Responses with Verbs Uninflected for Number in Experiment 3

\begin{tabular}{ccc}
\hline & \multicolumn{2}{c}{$\begin{array}{c}\text { Plurality of upstairs subject } \\
\text { and local subject }\end{array}$} \\
\cline { 2 - 3 } Animacy of local subject & Match & Mismatch \\
\hline Inanimate & 186 & 159 \\
Animate & 419 & 404 \\
\hline
\end{tabular}


iment, overlaid with the animacy effect obtained with the modified materials of the present experiment. We will restrict our presentation to the analyses of the agreement errors, the numbers and proportions of which are given in Table 10. In these analyses, the controls for the mismatch preambles were preambles matched with respect to the number of the upstairs subject (so the controls for mismatch items in which the upstairs subject was singular and the downstairs subject plural were match items in which the upstairs and downstairs subjects were both singular), analogous to the conditions of Experiment 2.

Analyses of variance yielded a significant main effect of number mismatch $[F(1,63)=34.40$ for participants; $F(1,31)=40.20$ for items $]$, with more errors for number-mismatching than for the number-matching subjects. Also significant were the interactions between mismatch and plurality $[F(1,63)=14.38$ for participants; $F(1,31)=8.43$ for items), reflecting the tendency for more second-verb agreement errors to follow plural than singular downstairs subjects in the mismatch condition only, and between mismatch and animacy $[F(1,63)=12.46$ for participants; $F(1,31)$ $=24.46$ for items], reflecting the preponderance of second-verb agreement errors associated with inanimate downstairs subjects in the mismatch conditions. The asymmetry between singulars and plurals was somewhat larger for animate than for inanimate downstairs subjects, but the three-way interaction was marginal for participants $[F(1,63)=3.82, p$ $<.06]$ and not reliable for items $[F(1,31)=2.55, p>.10]$. Finally, there was a significant main effect of animacy $[F(1,63)=6.62$ for participants; $F(1,31)=11.35$ for items], attributable to increased errors for inanimate relative to animate downstairs subjects.

\section{Discussion}

The results of Experiment 3 weaken the possibility that number agreement is dominated by the plurality of any preverbal noun, weighted ac-

TABLE 10

Numbers and Net Proportions of Second-Verb Agreement Errors in Experiment 3

\begin{tabular}{lccc}
\hline \multirow{2}{*}{$\begin{array}{c}\text { Animacy and number } \\
\text { of mismatch } \\
\text { downstairs subject }\end{array}$} & \multicolumn{2}{c}{$\begin{array}{c}\text { Number match between upstairs } \\
\text { and downstairs subject }\end{array}$} & $\begin{array}{c}\text { Net } \\
\text { proportion }\end{array}$ \\
\cline { 2 - 3 } & Mismatch & Match & .11 \\
\hline Animate plural & $21(.12)$ & $2(.01)$ & -.03 \\
Animate singular & $6(.03)$ & $6(.06)$ & .26 \\
Inanimatc plural & $35(.27)$ & $1(.01)$ & .18 \\
Inanimate singular & $30(.22)$ & $12(.04)$ & \\
\hline
\end{tabular}

Note. The proportions of errors in the mismatch and match conditions are shown in parentheses. 
cording to its serial position in the sentence, rather than by the plurality of the subject. If plurality and position alone determined agreement, the results for the first verbs in the sentences produced in Experiment 3 should have been similar to those of Experiment 2: Verbs should have agreed predominantly with the first noun phrase, and only occasionally with the local noun phrase. However, the results were reversed: The local noun's plurality was more strongly associated with correct agreement than the first noun's plurality. So the speakers were much more likely to say things such as The composer that the songs were. . than The composer that the songs was ... This can be readily explained by considering which of the two nouns was the syntactic subject of the first verb.

Variations in the animacy of the two nouns again had a massive influence on the type of the first verb used in the completions, with more uninflected, often lexical verbs appearing when the subject was animate. Inanimacy in the downstairs subject also disrupted the reproduction of the preambles, we suspect because downstairs-subject inanimacy made it difficult both to understand the intended relationships and to formulate an adequate completion. The essential difficulty is that of finding an adequate predication for an inanimate subject, exacerbated in this experiment by the requirement that the predication include the upstairs, animate subject as the implicit direct object of the relative clause.

This same problem yielded a consistent effect on first-verb agreement errors. There were more errors when the upstairs subjects were animate than when they were inanimate, and, most tellingly, this was true both when they were plural and when they were singular. The increase in agreement errors associated with singular animate upstairs subjects cannot be attributed to the aberrations of plural implementation, and suggests a genuine subject identification problem.

Comparison of the net error proportions in this experiment and those in the replication of Experiment 2 strengthens this argument (recall that the materials in the replication of Experiment 2 differed from the present one only in that they contained a preposition in the preambles, in place of the word that). This comparison is shown in Table 11, in terms of the features of the noun phrase with which the verbs erroneously agreed. There is a regular increase in the error proportions, primarily associated with the animacy of the nonsubject noun phrases in this experiment.

Further evidence for the subject-identification interpretation of the animacy effect comes from an analysis of the nature of the contents of the speakers' completions. It was sometimes possible to tell from the material in the relative clause whether the upstairs or downstairs subject was being used as the logical subject of the clause. For example, one speaker said The politician that the flags were waving . . . rather than something such as The politician that the flags were being waved by or The politician that 
TABLE 11

Change in Net Proportion of Agreement Errors from Experiment 2 (Replication) to Experiment 3

\begin{tabular}{lccr}
\hline $\begin{array}{c}\text { Animacy and number of } \\
\text { mismatch nonsubject } \\
\text { noun phrase }\end{array}$ & $\begin{array}{c}\text { Experiment 2 } \\
\text { (replication) }\end{array}$ & Experiment 3 & Change \\
\hline Inanimate singular & .01 & .03 & +.02 \\
Animate singular & -.03 & .06 & +.09 \\
Inanimate plural & .09 & .14 & +.05 \\
Animate plural & .05 & .26 & +.21 \\
\hline
\end{tabular}

the flags were waved for. We examined all the completions in the mismatch conditions to see how many logically congruent and incongruent completions there were, setting aside those that were indeterminate. We found no incongruent completions when the upstairs subject was inanimate. However, when it was animate, there were 168 congruent and 13 incongruent completions. We then looked at whether there were any affiliated consequences for agreement errors. The conditional probability of an agreement error given a congruent completion was .14; given an incongruent completion, it was .38. Thus, when speakers miscast the upstairs subject as the subject of the lower clause they were also more likely to make the verb agree with it in number.

It remains to be explained why the first-verb number-marking errors were associated not with plural local nouns but with plural upstairs subjects. The key may be that, in just this case, correct agreement was facilitated by the same processes that in Experiments 1 and 2 elicited errors: To the extent that singular-inflected verb forms were suppressed after plural downstairs subjects, they prevented the effect of the other type of error that occurred in Experiment 3, the subject-designation error, from appearing. Thus, the tendency created by a subject-designation problem toward the error The king that the islands rules would be counterweighed by the factors responsible for creating local agreement errors, which should favor the production of The king that the islands rule. No such counterweight would prevent errors such as The kings that the island rule. Mistakes consequently should be more likely when the upstairs subject is plural than when it is singular, not because the singular upstairs subject does not elicit errors, but because the plural downstairs subject accidentally corrects them.

One implication of this two-factor interpretation is that there should be fewer agreement errors after plural local nouns (downstairs subjects) in Experiment 3 than after the same plural local nouns in Experiment 2 (since the effect of a plural in Experiment 3 would be to correct an error that would otherwise occur). Conversely, after singular local nouns, 
agreement errors should increase in Experiment 3 relative to those in Experiment 2, because there is an additional cause for them in the subject designation error. The actual changes in the error proportions from Experiment 2 to Experiment 3, with respect to characteristics of the local nouns, were in line with these expectations. Among the agreementmarking responses after plural local nouns the net error proportion was .06 lower in Experiment 3 than in Experiment 2 (.04 lower than in the replication of Experiment 2), but after singular local nouns it was .22 higher (and .22 higher than in the replication of Experiment 2).

Second verbs. Except for the effect of animacy, the general distribution of responses and the agreement error patterns for second verbs (the verbs in the higher clauses of the sentences) were very similar to those for the verbs analyzed in Experiment 2. The error pattern tended to reflect the influence of the number of the subject noun in the relative clause which separated the upstairs subject from its verb, as did the local nouns in previous experiments. As before, this effect was somewhat larger when the intervening noun was plural than when it was singular, though the asymmetry is not as striking. This can be attributed to two factors, first to a tendency for the number of the second verb to be influenced by the number of the first verb, regardless of the number of the subject noun, and second to the presence of other nouns, uncontrolled for number, that appeared in the lower clauses of the sentences that the participants produced.

Like the first-verb errors, the second-verb errors revealed the influence of animacy. However, the effect is the mirror image of that for the first verbs, where there was a tendency for the verb to reflect the number of animate more than inanimate upstairs subjects. The second verbs took the leftover subjects, which tended to be the inanimate ones.

\section{GENERAL DISCUSSION}

We begin by summarizing the results of our experiments, particularly the findings for agreement errors. Then we proceed to a discussion of their implications for accounts of the production process. We conclude with a consideration of the viability of some of the claims about agreement errors that have appeared in the literature, in light of these results.

The first experiment showed that agreement errors occur in the laboratory under the same conditions that produce them naturally: When a sentential subject included a postmodifying noun phrase that differed from the head noun phrase in number, agrecment crrors arose. However, errors were much more likely when the subject was singular and the local noun phrase was plural, rather than the reverse, and were therefore more frequent when speakers completed a preamble such as The bridge to the 
islands than when they completed one such as The bridges to the island. Surprisingly, the length of the postmodifier had little impact on the occurrence of errors: Errors were just as frequent after The bridge to the islands as they were after The bridge to the popular coastal islands. This was not because preambles with short and long postmodifiers were equally easy to remember, since the speakers were much more likely to misproduce the latter than the former. However, this did not increase the likelihood of agreement errors.

The second experiment indicated that the animacy of the local noun does not enhance the occurrence of errors. Although sentence subjects are more often animate than not (Clark, 1965), an animate local noun phrase seemed to have no more privileges with respect to agreement than an inanimate one. This was not because the speakers were oblivious to animacy: The verbs selected for use with animate subjects were very different from the verbs selected for use with inanimate subjects. When the same head noun phrases appeared as local nouns, however, their animacy had no effect on agreement.

The results of the last experiment revealed the power of animacy over subject assignment. The same animacy differences that failed to affect agreement in Experiment 2 had a consistent effect in Experiment 3, when subject-assignment problems were created. This suggests that animacy matters to subject designation, which in turn matters to agreement. The other major finding from Experiment 3 is consistent with this view: When the local noun was actually the subject of the verb, the verb generally agreed with it and not the sentence-initial noun phrase. Together, the results argue that structural relations are a necessary part of the agreement process, ruling out a simpler interpretation that calls only on the plurality and position of preverbal noun phrases. For production purposes, agreement seems to be calculated with respect to abstract syntactic designations of subject.

\section{Agreement, Animacy, and Autonomy}

These results help to arbitrate, in one limited domain, between views of language processes that endorse open and relatively unconstrained interactions among various sorts of information (McClelland, 1987), and those committed to a more componential, modular, or autonomous system in which interactions are limited. With respect to agreement between subjects and verbs, this general issue takes the specific form of a question about the nature of the information that is available to and used by the mechanisms that implement agreement. Since it has been proposed (Givón, 1976) that agreement is better construed in terms of notional features of topics (such as animacy and definiteness) than in terms of syntactic features of subjects (such as location in clausal structure), 
agreement processes seem to provide a fair challenge for the alternative positions. The results indicate that agreement mechanisms are rather selective about the kinds of information they use, pointing to a noteworthy constraint on the interactions among information and processes in language production: A category feature (animacy) that is available to and used in the selection of sentence subjects is not used for the implementation of agreement between subjects and verbs.

The evidence for this is clearest in the comparison between Experiments 2 and 3. Experiment 2 suggested that animacy is not routinely involved in agreement. However, in Experiment 3, with pairs of noun phrases identical to those in Experiment 2, the results indicated that variations in animacy played a more consistent role in promoting agreement errors. The difference was that in Experiment 2, while there were agreement problems, there was no subject selection problem; in Experiment 3, there were subject selection problems, as well. When subject selection was not a problem, animacy did not affect the frequency of errors; when subject selection was a problem, agreement errors increased in frequency, and animacy was correlated with this increase.

This again confirms the relationship between animacy and subjecthood. The subjects of sentences are much more often animate than inanimate (Clark, 1965; MacWhinney, 1977); animates make more natural sentence subjects than inanimates (Clark \& Begun, 1971; Corrigan, 1986; Ransom, 1977); animates are moved from object to subject positions in sentence recall (Dewart, 1979; Harris, 1978); animates are selected as the logical subjects of asyntactic strings in which subjecthood is grammatically unspecified, whether the sentence is asyntactic (Bates et al., 1982; MacWhinney et al., 1984) or the person carrying out the interpretation is agrammatic (Saffran, Schwartz, \& Marin, 1980); and animates can govern more verbs in English than inanimates (Jarvella \& Sinnott, 1972). Similar claims apply to concreteness, construed as definiteness or specificity of reference (Bock \& Warren, 1985; James et al., 1973; Ransom, 1977).

The theoretical challenge is to explain how the flow of information is regulated during production such that information that is in principle available and useful to an operation, here subject-verb agreement, is ignored by it. One possibility was suggested by Bock (1987b). On this hypothesis, conceptual entities are linked to syntactic relations by mechanisms that are sensitive to their conceptual features. As a result, animacy and concreteness predispose certain kinds of syntactic role assignments, such that entities that are more animate (human rather than nonhuman animate; nonhuman animate rather than living inanimate; and so on) or more concrete (more definite) are better candidates for subject. However, once entities have been assigned the role of subject, the only 
thing that matters to a syntactic operation is the syntactic relation itself, and not the conceptual features of the place holder.

Other results are consistent with this claim. Bock and Warren (1985) manipulated the concreteness of the subject and object noun phrases of transitive sentences and the concreteness of conjoined noun phrases in sentences containing the conjunctions. When these sentences were produced (in the context of a reconstructive recall task), there was a strong tendency to place the more concrete noun in subject position, but none to place the more concrete noun first in the conjunction. This result would be hard to explain if ordering within sentences were claimed to be directly sensitive to the conceptual feature of concreteness. However, it makes sense from the perspective that ordering in adult speech is controlled by syntactic relations: Subjects go where they go (which is often first) because they are subjects, not because they are concrete entities. But since concrete entities are likely to be linked to the subject relation, they often get to go first. The two noun phrases in a conjunction both play the same syntactic role, so their relative concreteness makes no difference to their ordering.

With respect to subject-verb agreement, the picture that emerges is the following: Animacy influences the assignment of arguments to the subject relation, and the agreement mechanism operates with respect to that relation. If an incorrect subject is assigned under the influence of animacy, agreement will still be implemented with respect to the subject. Agreement errors may therefore appear because of an implicit error in subject assignment, not because of an error by the agreement mechanism in identifying the noun phrase with which the verb should agree.

The relative immutability of the subject relation with respect to agreement is also consistent with the claim that subject selection is carried out at a point in processing when the positions of the constituents of sentences have yet to be specified. Garrett (1975) proposed such a hypothesis to account for differences between word exchanges and sound exchanges in the distances they spanned, suggesting that word exchanges may arise when arguments are assigned to syntactic functions rather than to surface positions. On an account that follows these lines, the features of the verb that depend on the features of the subject may be indexed as soon as the subject and verb are specified, before they are linked to positions in the sentence. As a result, no errors of subject identification should occur except when another error causes an intended subject to be assigned a different syntactic relation. When this does occur, the verb form that appears nearly always agrees with the designated subject (rather than with the intended subject; Stemberger, 1985).

This hierarchical view of the production processes also helps to ac- 
count for the absence of length effects reported in Experiment 1. Because assignments to syntactic functions occur before the constituent structure of the sentence is built, and before serial position is spelled out, the length of the discontinuity between the head noun and verb, as well as the ability of a speaker to maintain information during the interruption, has little impact on agreement or agreement errors. Similarly, the relative inability of clausal postmodifiers to selectively disrupt agreement, suggested in the first experiment and confirmed by Bock and Cutting (1990), is consistent with a process that establishes agreement between elements before they are linearly ordered.

\section{The Causes of Agreement Errors}

This view of production helps to explain the locus of those errors of agreement that arise from subject identification problems, the restriction of the influence of animacy, and the absence of subject-verb distance and postmodifier complexity effects. What it does not immediately illuminate is the cause of the garden-variety error found in The time for fun and games are over. In this section we briefly consider some alternatives that may be given somewhat less credence on the basis of the data from these three experiments, as well as a class of more viable hypotheses.

Some unlikely candidates. The first casualties are a variety of simple frequency hypotheses (for example, that a more frequent verb form takes the place of a less frequent one). These stumble on the fact that the more common error involved the use of the less common form of the verb, the plural (to take one example, was and were have frequencies of 9816 and 3286, respectively, in the 1967 Kucera and Francis norms).

Second, simple memory hypotheses are blocked not only by the weak effects of the length of the postmodifier but by the fact that errors arise when the local noun is plural but not when it is singular. Failures to remember the subject should occur in more balanced fashion with singulars and plurals, if errors result from difficulties in recalling the subject or its number.

Other explanations that postulate a principled, grammatical basis for this type of agreement pattern also received little support. The first of these is the reference-based hypothesis, according to which agreement operates between the mentally fixed number of the entity denoted by the whole preamble. In Experiment 1 we contrasted items in which this number was likely to have been singular (the bridge to the islands) with items in which this number may have been plural (the picture on the postcards) and found no difference between them in the elicitation of errors. Along related lines, Experiment 2 and its replication failed to find consistent effects of the relative concreteness of the head and local nouns.

Finally, it has been suggested that such errors may represent dialectal 
deviations from the standard pattern. Francis (1986) indeed proposed that proximity concord (agreement between verbs and local nouns) is "on the verge of being standardized" (p. 311). Setting aside the anomaly that proximity concord occurs only for plurals, this hypothesis predicts that there should be speakers who find proximity concord acceptable and standardly use it in their speech. Such speakers should prefer proximity concord to subject concord in judgment tasks, and should be more likely to produce verb agreement errors in the fragment completion task.

We examined this possibility in Experiment 2, the replication of Experiment 2, and Experiment 3, by asking participants at the end of each session which of the following forms is the correct one: ${ }^{6}$

1) The impact of the cuts has not hit yet.

2) The impact of the cuts have not hit yet.

Performance on this forced-choice task was much worse than would be expected on the basis of the number of agreement errors that the speakers actually produced: Only $60 \%$ of the 192 participants chose the correct version (version 1 above). In contrast, $95 \%$ of all the agreement-marking responses in the preamble completions were correct. ${ }^{7}$ More to the point, there was no relationship at all between performance on the judgment task and performance on the preamble completion task. Overall, the 77 participants who chose the incorrect version of the sentence in the judgment task produced a mean of .39 errors in the mismatch conditions in the speaking task, while the 115 who chose the correct version actually produced slightly but nonsignificantly more errors, a mean of .42 [two-tailed $t(190)=.20]$.

This random distribution of speaking errors is understandable if they are truly errors, not a uniform dialectal option, and their rarity among the agreement-marking responses reinforces this conclusion. Strang (1966)

\footnotetext{
${ }^{6}$ The forced-choice item presented to the participants was composed with an eye toward two errors that Francis reported in his corpus, The full impact of the cuts haven't hit hard as yet and ... see what the impact of some of these changes are (Francis, 1986, p. 318). We reasoned that if this agreement pattern is employed primarily by speakers for whom it is the standard, the fairest test would consist of something resembling an actual utterance from such a speaker.

${ }^{7}$ We are not sure why performance on the judgment task was so poor, but it is interesting that agreement is one of the few features of English grammar that are intensively drilled, along with explicit exemplification of incorrect forms. For example, one 10th grade grammar used in schools in the United States (Warriner et al., 1965) devotes an entire chapter to agreement, with an exercise set of 20 sentence pairs much like the one we employed in our judgment test. Many of the participants were suspicious about the test and, perhaps stirred by deep-rooted memories of such exercises, expressed the belief that there was some trick to it. Morgan (1972) also observed wide variations in judgments about agreement in a group of 20 informants, who were very likely more linguistically sophisticated than ours, suggesting that whatever the problem, it is not unique to our sample.
} 
reported that the rate of agreement violations per individual student was close to the average rate in her corpus. Our experimental participants likewise showed little variability in the production of errors. The variability of judgment and the relative invariability of agreement in use suggest that dialectal differences in agreement patterns are not a sufficient explanation for the agreement pattern we observed.

Some remaining alternatives. What, then, does cause these aberrations? We do not yet have a final answer to this question, and there may be no single, simple answer. However, all three experiments implied that something connected with plurality itself bears heavy responsibility for agreement errors. Overwhelmingly, the plurality of a local noun phrase was associated with agreement problems, when singularity was not. What needs to be explained is how number implementation goes awry in the presence of an extraneous plural, at a point when the relation between the verb and the head noun is irrelevant to processing (since the evidence suggests that the problem does not involve the specification of the head noun).

The simplest hypothesis, one alluded to by Strang (1966) and Zandvoort (1961), is a phonological one. Since the plural and the third-person singular inflections are identical $(/ \mathrm{s} /, / \mathrm{z} /$, and $/ \mathrm{zz} /)$, the selection of the plural on a noun may complicate the creation of a homophonous form on the verb, perhaps because of the postselection inhibition that is required to keep us from repeating ourselves endlessly (MacKay, 1987). ${ }^{8}$ A comparable force seems to be responsible for a constraint on adult speech production examined by Stemberger and MacWhinney (1986; also see Menn \& MacWhinney, 1984). Stemberger and MacWhinney found that zeromarking errors on past tense verb forms (errors in which a speaker says guide instead of guided, for example) occur almost exclusively when the verb already ends in /t/ or /d/. A similar constraint probably governs zero-marking errors on plural nouns that already end in $/ \mathrm{s} /$ or $/ \mathrm{z} /$ (Berko, 1958). To account for such errors, Stemberger and MacWhinney proposed a mechanism of affix checking, according to which affixes fail to apply when they "find themselves" already instantiated in the developing string. Applied to the present problem, we might predict sequences such as islands needs (as in The bridge to the islands needs to be repaired) to be avoided in favor of sequences in which the affix appears just once, yielding the error illustrated in The bridge to the islands need to be repaired.

Despite its attractiveness, we have found no support for this possibility

${ }^{8}$ If similarity of phonology is sufficient to cause this disruption, the same effect would occur for the forms of to be, since the singular forms (is, was) contain $/ \mathrm{z} /$ and the plurals (are, were) do not. 
in ongoing research (Bock \& Eberhard, 1990). Comparing agreement errors after preambles such as The player on the court, the player on the course, and The player on the courts, where the same phonological but different plurality constraints govern the last two preambles, we obtained agreement errors only after true plural local nouns. No errors at all occurred after singular local nouns of either type.

A remaining conjecture is that affix checking or something like it could, in the case of agreement marking, involve a common morphophonological specification of the number markers for nouns and verbs, and we are investigating this option. It is again linked to the idea that the implementation of the plural inflection on the noun suppresses the singular inflection on the verb at a point in processing when the linkage between number and the subject relation is inoperative. However, it stands on the assumption of a common morphophonological representation for plural and thirdperson-singular affixes, and thereby fails to account for the bulk of agreement errors, those involving irregular verb forms.

Whatever the eventual resolution of this problem, the major challenge to the explanation of agreement errors, like other speech errors, is their exceptional nature. To be viable, any account must be compatible with, and preferably complement, an explanation of the implementation of correct, unexceptional agreement, represented in $95 \%$ of the responses with verbs that were inflected for number in the present work. Since half of our conditions were specifically designed to elicit errors, errors are unlikely to be more common when the entire range of agreement-requiring situations is considered.

\section{Some Limitations}

There are important shortcomings of these results, some attributable to the task we employed and some to the nature of the responses we elicited. The task departed from the ideal production paradigm in that it demanded interpretations and reproductions of the verhal, experimenter-provided preambles, and defects in the requisite subprocesses of perception, comprehension, and memory may have prompted unsuspected departures from normal production. Though we attempted to control for these artifactual influences by setting the results for the experimental preambles against those for preambles that differed only with respect to the marking of number, a cleaner and more ingenious technique could perhaps bypass these contaminants more surely.

The problems created by the responses themselves grow out of the heavy weighting toward auxiliary and copula verb use, and hence toward irregular verb forms. We observed relatively few errors (or correct responses, for that matter) involving regular, third-person present verb forms. Likewise, very few of the spontaneously produced agreement er- 
rors in the corpora available to us involved regular verbs. These disparities merely reflect actual distributions in the use of regularly and irregularly inflected verb forms (Svartvik, 1966). But regardless of their ecological validity, the bias imposes an a priori restriction on the interpretation of the results. Until it can be shown conclusively that regular verbs are subject to the same agreement forces, it remains possible that the proper account of agreement errors will implicate verbs whose forms may be directly retrieved rather than constructed.

We cannot provide this conclusive proof, but we will offer the data at our disposal about the error rates and singular/plural distributions for regular and irregular verb forms. In the first two experiments, 42 regular verb forms were used, 2 of them in errors, for an error rate of $4.8 \%$. In comparison, 1624 irregular forms were used, 125 of them in errors, for a rate of $7.7 \%$. The tendency for plural verb forms to be associated with errors was virtually identical for the two types, however, with an error rate that was . 10 higher for plural than for singular verb forms in each case ( $2 / 21$ to $0 / 21$ for the regulars and $102 / 814$ to $23 / 810$ for the irregulars). Although the naturalistic error corpora do not permit direct estimations of error rates, we can look at the numbers of regular and irregular verbs represented. Regular verbs accounted for $20 \%$ of the 83 mistakes, and of these .88 represented the plural form. For the irregular verb errors, .80 represented the plural form. On the basis of these limited samples, then, it appears that asymmetric distributions of errors with respect to singular and plural forms may hold for both regular and irregular verbs, though it remains to be determined whether the overall rates of error differ.

\section{CONCLUSION}

We began this work armed with some theoretical predictions as well as some intuitive preconceptions about verb agreement errors. In general, the only account that fared well was one suggesting that what controls and mediates agreement is the abstract syntactic relation of subject, not the notional properties and positions of noun phrases. Accordingly, the animacy of a preverbal noun phrase, on its own, had little to do with whether verb agreement errors occurred. Only when the preverbal noun was also the subject of the verb were its features relevant to the occurrence of error, by way of the privileges of those features with respect to the subject relation. Since subjecthood seems to be fixed before word order and the phonological forms of words are specified, the distance to the verb and the ability to remember verbatim details likewise bore little relation to the occurrence of error. Along with other aberrations of sentence production, then, agreement errors suggest strong and interesting constraints on the use of information that is in principle available to the speaker. 


\section{APPENDIX}

Basic Sentence Preambles for Experiment I (Parenthesized Material Appeared Only in the Long Conditions)

1. The slogan on the (candidate's campaign) poster

2. The label on the (tamper-proof medicine) bottle

3. The name on the (enormous highway) billboard

4. The picture on the (turn-of-the-century) postcard

5. The problem in the (wealthy suburban) school

6. The defect in the (new General Motors) car

7. The mistake in the (administration's social) program

8. The crime in the (older industrial) city

9. The memo from the (inexperienced tax) accountant

10. The letter from the (real estate company's) lawyer

11. The warning from the (California earthquake) expert

12. The check from the (indicted Wall Street) stockbroker

13. The key to the (ornate Victorian) cabinet

14. The door to the (president's private) office

15. The bridge to the (popular coastal) island

16. The entrance to the (world-famous biology) laboratory

17. The tile used to cover the (restored cathedral) floor

18. The guard employed for the (arms-reduction treaty signing) ceremony

19. The actor hired to do the (Burger King television) commercial

20. The computer installed in the (Russian antiballistic) missile

21. The mechanic who repaired the (limousine's rear) tire

22. The detective who solved the (Los Angeles freeway) murder

23. The professor who criticized the (university's new) dean

24. The receptionist who greeted the (corporation's distinguished) visitor

25. The boy that liked the (colorful garter) snake

26. The dog that chased the (noisy trailer) truck

27. The astronomer that discovered the (most distant) galaxy

28. The company that claimed the (author's disputed) copyright

29. The table that the (volunteer college) student painted

30. The girl that the (high school science) teacher questioned

31. The soldier that the (battalion's senior) officer accused

32. The policy that the (southern Republican) governor recommended

\section{REFERENCES}

Anderson, J. R. (1983). The architecture of cognition. Cambridge, MA: Harvard Univ. Press. 
Baars, B. J., Motley, M. T., \& MacKay, D. G. (1975). Output editing for lexical status in artificially elicited slips of the tongue. Journal of Verbal Learning and Verbal Behavior, 14, 382-391.

Bach, E. (1974). Syntactic theory. New York: Holt, Rinehart, \& Winston.

Bates, E., McNew, S., MacWhinney, B., Devescovi, A., \& Smith, S. (1982). Functional constraints on sentence processing: A cross-linguistic study. Cognition, 11, 245-299.

Berko, J. (1958). The child's learning of English morphology. Word, 14, 150-177.

Bock, J. K. (1987a). An effect of the accessibility of word forms on sentence structures. Journal of Memory and Language, 26, 119-137.

Bock, J. K. (1987b). Coordinating words and syntax in speech plans. In A. Ellis (Ed.), Progress in the psychology of language (pp. 337-390). London: Erlbaum.

Bock, J. K., \& Cutting. J. C. (1989). Regulating mental energy: Performance units in language production, manuscript submitted for publication.

Bock, J. K., \& Eberhard, K. M. (1990). The implementation of number marking for subject-verb agreement, manuscript in preparation.

Bock, J. K., \& Kroch, A. S. (1989). The isolability of syntactic processing. In G. N. Carlson \& M. K. Tanenhaus (Eds.), Linguistic structure in language processing (pp. 157196). Dordrecht: Kluwer.

Bock, J. K., \& Loebell, H. (1990). Framing sentences. Cognition, 35, 1-39.

Bock, J. K., \& Warren, R. K. (1985). Conceptual accessibility and syntactic structure in sentence formulation. Cognition, 21, 47-67.

Bresnan, J., \& Kaplan, R. M. (1984). Grammars as mental representations of language. In W. Kintsch, J. R. Miller, \& P. G. Polson (Eds.), Method and tactics in cognitive science (pp. 103-135). Hillsdale, NJ: Erlbaum.

Butterworth, B. (1980). Some constraints on models of language production. In B. Butterworth (Ed.), Language production: Vol. 1: Speech and talk (pp. 423-459). London: Academic Press.

Caplan, D. (1972). Clause boundaries and recognition latencies for words in sentences. Perception \& Psychophysics, 12, 73-76.

Chomsky, N. (1965). Aspects of the theory of syntax. Cambridge, MA: MIT Press.

Clark, H. H. (1965). Some structural properties of simple active and passive sentences. Journal of Verbal Learning and Verbal Behavior, 4, 365-370.

Clark, H. H., \& Begun, J. S. (1971). The semantics of sentence subjects. Language and Speech, 14, 34-46.

Clark, H. H., \& Malt, B. C. (1984). Psychological constraints on language: A commentary on Bresnan and Kaplan and on Givón. In W. Kintsch, J. R. Miller, \& P. G. Polson (Eds.), Method and tactics in cognitive science (pp. 191-214). Hillsdale, NJ: Erlbaum.

Clark, H. H., \& Stafford, R. A. (1969). Memory for semantic features in the verb. Journal of Experimental Psychology, 80, 326-334.

Corbett, G. G. (1988). Agreement: A partial specification based on Slavonic data. In M. Barlow \& C. A. Ferguson (Eds.), Agreement in natural language (pp. 23-53). Stanford, CA: Center for the Study of Language and Information.

Corrigan, R. (1986). The internal structure of English transitive sentences. Memory \& Cognition, $14,420-431$.

Daneman, M., \& Green, I. (1986). Individual differences in comprehending and producing words in context. Journal of Memory and Language, 25, 1-18.

Danks, J. H. (1984). Review of "Effects of number: Experimental studies of the grammatical atmosphere effect" by J. W. Mann. American Journal of Psychology, 97, 611-612.

Dell, G. S. (1986). A spreading-activation theory of retrieval in sentence production. Psychological Review, 93, 283-321. 
Dell, G. S., \& Reich, P. A. (1981). Stages in sentence production: An analysis of speech error data. Journal of Verbal Learning and Verbal Behavior, 20, 611-629.

Demuth, K. A. (1988). Noun classes and agreement in Sesotho acquisition. In M. Barlow \& C. A. Ferguson (Eds.), Agreement in natural language (pp. 305-321). Stanford, CA: Center for the Study of Language and Information.

Dewart, M. H. (1979). Role of animate and inanimate nouns in determining sentence voice. British Journal of Psychology, 70, 135-141.

Fay, D., \& Cutler, A. (1977). Malapropisms and the structure of the mental lexicon. Linguistic Inquiry, 8, 505-520.

Fodor, J. A. (1983). The modularity of mind. Cambridge, MA: MIT Press.

Follett, W. (1966). Modern American usage; A guide. New York: Hill \& Wang.

Fowler, H. W. (1937). A dictionary of modern English usage. Oxford: Oxford Univ. Press.

Francis, W. N. (1986). Proximity concord in English. Journal of English Linguistics, 19, 309-318.

Fromkin, V. A. (1971). The non-anomalous nature of anomalous utterances. Language, 47, 27-52.

Garrett, M. F. (1975). The analysis of sentence production. In G. H. Bower (Ed.), The psychology of learning and motivation (pp. 133-177). New York: Academic Press.

Garrett, M. F. (1976). Syntactic processes in sentence production. In R. J. Wales \& E. C. T. Walker (Eds.), New approaches to language mechanisms (pp. 231-256). Amsterdam: North-Holland.

Garrett, M. F. (1980). Levels of processing in sentence production. In B. Butterworth (Ed.), Language production: Vol. I: Speech and talk (pp. 177-220). London: Academic Press.

Gazdar, G., Klein, E., Pullum, G., \& Sag, 1. (1985). Generalized phrase structure grammar. Cambridge, MA: Harvard Univ. Press.

Gilhooly, K. J., \& Logie, R. H. (1980a). Age-of-acquisition, imagery, concreteness, familiarity, and ambiguity measures for 1,944 words. Behavior Research Methods \& Instrumentation, 12, 395-427.

Gilhooly, K. J., \& Logie, R. H. (1980b). Meaning-dependent ratings of imagery, age of acquisition, familiarity, and concreteness for 387 ambiguous words. Behavior Research Methods \& Instrumentation, 12, 428-450.

Givón, T. (1976). Topic, pronoun, and grammatical agreement. In C. N. Li (Ed.), Subject and topic (pp. 149-188). New York: Academic Press.

Harley, T. A. (1984). A critique of top-down independent levels models of speech production: Evidence from non-plan-internal speech errors. Cognitive Science, 8, 191-219.

Harris, M. (1978). Noun animacy and the passive voice: A developmental approach. Quarterly .Iournal of Experimental Psycholngy, 30, 495-501.

Harris, R. J., \& Brewer, W. F. (1973). Deixis in memory for verb tense. Journal of Verbal Learning and Verbal Behavior, 12, 590-597.

James, C. T., Thompson, J. G., \& Baldwin, J. M. (1973). The reconstructive process in sentence memory. Journal of Verbal Learning and Verbal Behavior, 12, 51-63.

Jarvella, R. J. (1971). Syntactic processing of connected speech. Journal of Verbal Learning and Verbal Behavior, 10, 409-416.

Jarvella, R. J., \& Sinnott, J. (1972). Contextual constraints on noun distributions to some English verbs by children and adults. Journal of Verbal Learning and Verbal Behavior, 11, 47-53.

Jespersen, O. (1924). The philosophy of grammar. London: Allen \& Unwin.

Keenan, E. L. (1974). The functional principle: Generalizing the notion of 'subject of'. In M. W. LaGaly, R. A. Fox, \& A. Bruck (Eds.), Papers from the tenth regional meeting of the Chicago Linguistic Society (pp. 298-309). Chicago, IL: Chicago Linguistic Society. 
Keeney, T. J., \& Wolfe, J. (1972). The acquisition of agreement in English. Journal of Verbal Learning and Verbal Behavior, 11, 698-705.

Keil, F. C. (1979). Semantic and conceptual development. Cambridge, MA: Harvard Univ. Press.

Kempen, G., \& Hoenkamp, E. (1987). An incremental procedural grammar for sentence formulation. Cognitive Science, 11, 201-258.

Kilborn, K. (1988). A note on the on-line nature of discourse processing: Comparing behavioral and electrophysiological measures in monitoring for semantic anomalies and grammatical errors, manuscript submitted for publication.

Klaiman, M. H. (1988, September). Higher entity phenumena in grammar. Paper presented at the Minnesota Conference on Language and Linguistics, Minneapolis, MN.

Kucera, H., \& Francis, W. N. (1967). Computational analysis of present-day American English. Providence: Brown Univ. Press.

Kutas, M., \& Hillyard, S. A. (1983). Event-related brain potentials to grammatical errors and semantic anomalies. Memory \& Cognition, 11, 539-550.

Lapointe, S. G., \& Dell, G. S. (1989). A synthesis of some recent work in sentence production. In G. N. Carlson \& M. K. Tanenhaus (Eds.), Linguistic structure in language processing (pp. 107-156). Dordrecht: Kluwer.

Levelt, W. J. M. (1983). Monitoring and self-repair in speech. Cognition, 14, 41-104.

Levelt, W. J. M. (1989). Speaking: From intention to articulation. Cambridge, MA: MIT Press.

Levelt, W., \& Maassen, B. (1981). Lexical search and order of mention in sentence production. In W. Klein \& W. Levelt (Eds.), Crossing the boundaries in linguistics (pp. 221-252). Dordrecht: Reidel.

Lyons, J. (1969). Introduction to theoretical linguistics. Cambridge: Cambridge Univ. Press.

MacKay, D. G. (1987). The organization of perception and action. New York: SpringerVerlag.

MacWhinney, B. (1977). Starting points. Language, 53, 152-168.

MacWhinney, B., Bates, E., \& Kliegl, R. (1984). Cue validity and sentence interpretation in English, German, and Italian. Journal of Verbal Learning and Verbal Behavior, 23, 127-150.

Mann, J. W. (1982a). Atmosphere or red herring? Journal of General Psychology, 106, 159-163.

Mann, J. W. (1982b). Effects of number: Experimental studies of the grammatical atmosphere effect. Johannesburg: Witwatersrand Univ. Press.

Martin, N., Weisberg, R. W., \& Saffran, E. M. (1989). Variables influencing the occurrence of naming errors: Implications for models of lexical retrieval. Journal of Memory and Language, 28, 462-485.

McClelland, J. L. (1987). The case for interactionism in language processing. In M. Coltheart (Ed.), Attention and performance XII: The psychology of reading (pp. 3-36). Hillsdale, NJ: Erlbaum.

Menn, L., \& MacWhinney, B. (1984). The repeated morph constraint: Toward an explanation. Language, 60, 519-541.

Morgan, J. L. (1972). Verb agreement as a rule of English. In P. M. Peranteau, J. N. Levi, \& G. C. Phares (Eds.), Papers from the Eighth Regional Meeting, Chicago Linguistic Society (pp. 278-286). Chicago, IL: Chicago Linguistic Society.

Paivio, A., Yuille, J. C., \& Madigan, S. A. (1968). Concreteness, imagery, and meaningfulness values for 925 nouns. Journal of Experimental Psychology Monograph Supplement, 76(1, Pt. 2).

Pollard, C., \& Sag, I. A. (1988). An information-based theory of agreement. In D. Brentari, G. Larson, \& L. MacLeod (Eds.), Papers from the 24th Annual Regional Meeting of 
the Chicago Linguistic Society, Part Two: Parasession on Agreement in Grammatical Theory (pp. 236-257). Chicago, IL: Chicago Linguistic Society.

Quirk, R., Greenbaum, S., Leech, G., \& Svartvik, J. (1972). A grammar of contemporary English. New York: Seminar Press.

Ransom, E. N. (1977). Definiteness, animacy, and NP ordering. In K. Whistler, R. D. van Valin, Jr., C. Chiarello, J. J. Jaeger, M. Petruck, H. Thompson, R. Javkin, \& A. Woodbury (Eds.), Proceedings of the 3rd Annual Meeting of the Berkeley Linguistics Society (pp. 418-429). Berkeley: Berkeley Linguistics Society.

Saffran, E. M., Schwartz, M. F., \& Marin, O. S. M. (1980). Evidence from aphasia: Isolating the components of a production model. In B. Butterworth (Ed.), Language production: Vol. 1: Speech and talk (pp. 221-241). London: Academic Press.

Sells, P. (1985). Lectures on contemporary syntactic theories. Stanford, CA: Center for the Study of Language and Information.

Shattuck-Hufnagel, S. (1979). Speech errors as evidence for a serial-ordering mechanism in sentence production. In W. E. Cooper \& E. C. T. Walker (Eds.), Sentence processing: Psycholinguistic studies presented to Merrill Garrett (pp. 295-342). Hillsdale, NJ: Erlbaum.

Spreen, O., \& Schulz, R. W. (1966). Parameters of abstraction, meaningfulness, and pronunciability for 329 nouns. Journal of Verbal Learning and Verbal Behavior, 5, 459468.

Stemberger, J. P. (1985). An interactive activation model of language production. In A. Ellis (Ed.), Progress in the psychology of language (pp. 143-186). London: Erlbaum.

Stemberger, J. P., \& MacWhinney, B. (1986). Form-oriented inflectional errors in language processing. Cognitive Psychology, 18, 329-354.

Strang, B. M. H. (1966). Some features of S-V concord in present-day English. In I. Cellini \& G. Melchiori (Eds.), English studies today: Fourth series (pp. 73-87). Rome, Italy: Edizioni di Storia e Letteratura.

Svartvik. J. (1966). On voice in the English verb. The Hague: Mouton.

Warriner, J. E., Renison, W., \& Griffith, F. (1965). English grammar and composition. New York: Harcourt, Brace \& World.

Woodworth, R. S. (1938). Experimental psychology. New York: Holt.

Zandvoort, R. W. (1961). Varia syntactica. In Language and society: Essays presented to Arthur M. Jensen on his seventieth birthday (pp. 193-203). Copenhagen, Denmark: Det Berlingske Bogtrykkeri.

(Accepted January 9, 1990) 